\title{
LA HISTORIA ECONOMICA DE PORTUGAL (SIGLOS XIX Y XX) ${ }^{1}$
}

\author{
ELOY FERNANDEZ CLEMENTE \\ Universidad de Zaragoza
}

\section{INTRODUCCION}

La historiografía económica portuguesa ha experimentado un gran cambio en los últimos quince años, a pesar de las dificultades no ya políticas, pero sí materiales; por ejemplo, la situación de los Archivos ${ }^{2}$. Como escribiera Albert Silbert en 1979, la historia económica portuguesa «sufre de un atraso del que los historiadores no tienen toda la culpa». Además, y de ahí el posible interés de este informe, las cosas han cambiado mucho desde abril de $1974^{3}$, aunque casi siempre enlazando con lo realizado en las últimas

- Este trabajo ha sido posible gracias a una ayuda del Consejo Asesor de Investigación de la Diputación General de Aragón y la Caja de la Inmaculada (CAI-CONAI), gracias a la cual permanecí en Lisboa el mes de julio de 1987. Debo agradecer la cordial y eficaz acogida de los colegas portugueses, en especial de los profesores Miriam Halpern Pereira, Jaime Reis, Magda Pinheiro y Pedro Laíns. A estos dos últimos, también sus correcciones y sugerencias, así como a Santiago Zapata (Universidad de Extremadura), Xan Carmona (Universidad de Santiago) y a mis colegas de Zaragoza, Luis Germán, Domingo Gallego y Vicente Pinilla. Los errores son, desde luego, de mi responsabilidad, al igual que las traducciones de citas, la grafía, etc. Debo advertir que sigo la norma portuguesa de considerar el último de los apellidos como principal.

${ }^{2}$ J. Serrāo, M. J. Leal, M. H. Pereira (1983-85). En el tomo 3 se quejan M. J. Silva y Miriam Halpern Pereira de la einexistencia en el Archivo Nacional de documentación de la administración central sobre los siglos XIX y xx, equivalente a la allí depositada relativa a los períodos anteriores. Líneas de investigación fundamentales de la historiografía con. temporánea permanecen bloqueadas por la inaccesibilidad al "Archivo de las Secretarías de Estado", depósito de ciento cincuenta años de documentación administrativa instalado en barracones de la Marina en Amora, pero inaccesible por razones técnicas. Además, en los ministerios en que se construyen archivos históricos, una obsoleta legislación limita la investigación por el mantenimiento de un período de confidencialidad demasiado largo* (pp. 15-16). En parecido sentido, las quejas de Fernando Rosas en la apertura en 1986 del Congreso sobre "O Estado Novo». En los últimos años han aparecido, aparte el magnífico repertorio que son ya los tres tomos del Roteiro citado, varios trabajos de mucha menor cuantía sobre archivos y bibliotecas en diversas revistas de historia. De muy reciente aparición: Arquivo e bistoriografia, Actas del Coloquio sobre Fontes da História Contemporánea Portuguesa, Imprensa Nacional, Lisboa, 1988.

${ }^{3}$ El 80 por 100 de los trabajos citados son posteriores a 1974. Hagamos, sobre todo, referencia al trabajo universitario, muy destacadamente en las Facultades de Economía y de Ciencias Sociales y Humanas de la Universidade Nova de Lisboa, de cuyos profesores 
décadas del salazarismo, bien en el exilio, bien dentro, a pesar de las dificultades de la dictadura. En aquella época fue manifiesta la influencia desde París de Fernand Braudel, Pierre Vilar, Albert Silbert, Jean Bouvier, etc.; en torno a ellos se han formado muchos de los principales especialistas en Historia Económica de Portugal, artífices de una renovación ejemplar.

Entre las principales fuentes y repertorios generales, citemos la Guia de Bibliografía Histórica (1959), editada por la Academia Portuguesa da História; la Bibliografía económica, de Guerreiro (1970); el Diccionario de História de Portugal, dirigido por Joel Serrão (1985a), o el renacer de los estudios sobre Portugal y Brasil en las universidades norteamericanas (Kettenring). También la veterana Bibliografía Geográfica (reeditado el tomo de Feio de hace cuarenta años, se le une un segundo de Amaral y Daveau, 1982), y en general los estudios de los padres de la moderna historiografía portuguesa, como Antònio Sergio, J. Cortesâo, L. de Azevedo, Virginia Rau, etcétera, y la escuela geográfica que preside Orlando Ribeiro. Entre los estudios económicos de ámbito territorial, el de J. Mayer (1981), y de las diversas historias generales, la ya clásica de Damião Peres y la reciente de A. H. de Oliveira Marques (1977). Citemos tan sólo - ya que no podemos estudiarlo aquí y ahora - el importante tema del movimiento obrero, del que, por otra parte, poseemos escasa información ${ }^{4}$.

Una visión de conjunto. Es el desarrollo regional una gran obsesión portuguesa, si bien hasta muy recientemente no se ha planteado un tratamiento de la descentralización regional. La tesis doctoral de David Justino, $A$ formação do espaço económico nacional. Portugal $1810-1913(1986)^{5}$ estudia la es-

haremos repetida cita. También, el Instituto de Ciencias Sociais, el ICSTE y otros organismos próximos a la Universidad. Aunque la mayor parte de los historiadores de la economía viven y trabajan en Lisboa, hay destacados grupos en Oporto, Coimbra, Evora (donde Elder Adegar Fonseca trabaja en Historia de las Empresas Agrarias), etc. La activa Associação Portuguesa de História Económica e Social celebró en abril de 1987 su décimo encuentro, en Coimbra, con un notable nivel. Lo mismo podemos decir de las importantes revistas Análise Social, Revista de História Económica e Social, Ler História y unas cuantas más, que iremos citando.

4 La historia del movimiento obrero ha sido, por razones bien obvias, uno de los temas menos desarrollados durante la etapa salazarista. A los estudios ya clásicos de Alexandre Vieira (reeditado en 1974), M. J. de Sousa, etc., han venido a sumarse los de Carlos da Fonseca, César Nogueira (1964-66), César de Oliveira (1974), M. P. de Lima (1980), M. Silva (1980), M. H. Pereira $(1982,1983)$ y, sobre todo, los de M.' Filomena Mónica (1982 $a$ y $b, 1985,1986)$, que muestran un notable progreso metodológico y conceptual, manifestado en el extra monográfico dedicado al tema en Análise Social (1981), en el que destacaríamos el estudio de J. M. Tengarrinha sobre la historia de las huelgas. También es muy interesante el estudio para 1917-25 de Fernando Medeiros (1978).

5 La tesis de Justino, que ve luz editorial con este trabajo en prensa (Ed. Vega, Lisboa, 1988, 2 vols.), contiene mucha información estadística inédita, tanto sobre industria como sobre agricultura y precios, constituyendo hoy la principal fuente impresa sobre el siglo $\mathrm{XIX}$. 
tructura económica y las disparidades regionales en Portugal, a mediados del xIx y, en relación con ellas, el crecimiento económico, la formación de un mercado nacional, etc. Justino revisa las tesis de P. Bairoch, en el sentido de que Portugal tuvo «un crecimiento lento en relación con la mayor parte de los países europeos, en el mismo período, en especial los llamados países del "centro", que presentan tasas de crecimiento superiores al 1 por 100 anual, para la segunda mitad del siglo XIX".

Según la periodización formulada por este autor, Portugal tuvo un crecimiento generalizado en los quince años que siguen a la definitiva implantación del régimen liberal (1834-48). A la gran quiebra de 1853-57 (llega a reducirse cerca del 22 por 100 del PNB/habitante) por una crisis agrícola, sigue en la década de los 60 un crecimiento extremadamente lento, una tendencia recesiva en la producción agrícola y pecuaria; más rápido es en los primeros 70 , hasta la crisis de 1876. A mediados de los 80 , una nueva expansión (vino, aflujo de capitales exteriores, la mejor tasa de crecimiento industrial hasta la Primera Guerra Mundial), hasta 1891-92, en que aparece una nueva crisis. No es, pues, un crecimiento continuo. Hay, además, una notable desarticulación sectorial y una débil articulación regional (quizá debido a la estructura del mercado interior, que refleja un determinado nivel de división social del trabajo); la agricultura sería, según Justino, más bloqueadora que dinamizadora.

¿Y las otras transformaciones estructurales? Es preciso atender al marco jurídico, los transportes, la circulación de mercancías, las relaciones entre autoconsumo y mercado, el papel del Estado como inversor y redistribuidor de rendimientos, la política arancelaria y bancaria, etc. Y a lo que Justino llama "de la crisis del centro al surgir de las "periferias": un largo proceso de desestructuración». El mercado interior va a tener una nueva dimensión, predominando el sur triguero, potenciado su papel integrador frente al norte, más dinámico en la primera mitad del xIX. El proceso reorganizador parte de Lisboa, pero ese crecimiento, lento, sectorial regionalmente desarticulado, resulta de ser la población tan sólo el 1,19 por 100 de la europea hacia 1900 , con una lenta expansión de su mercado, con un bajo índice urbano (en 1910, sólo el 16,7 por 100 de la población vive en ciudades de más de 5.000 habitantes, menos de la mitad que la media europea de entonces), el débil desarrollo de las clases medias, el atraso educativo... Un mercado nacional -concluye David Justino- supone la acción del Estado y una voluntad política unificadora, generalmente asociada a la idea de Nación. También presupone una elevada movilidad geográfica de los bienes y factores de producción, y depende del grado de «división regional del trabajo», proyección espacial de la división social del trabajo, y de un centro económicamente dominante, que es, sin duda alguna, Lisboa. 
Otra serie de trabajos de un destacado grupo de investigadores que iremos citando más adelante ha contribuido a la perspectiva de conjunto presentando series de macromagnitudes: desde los lejanos intentos de Guerreiro (1948) a los de Nuno Valerio (primera estimación del producto nacional, 1983), Jaime Reis (producción industrial, 1985), Pedro Laíns (comercio exterior y producción agraria, 1986, 1987, 1988) y David Justino (la evolución del PNB, 1987); mientras que la obra de conjunto de Miriam Halpern Pereira (1984), afortunadamente traducida y editada en parte (aunque no su obra más sistemática y teórica) en español, son los principales enfoques globalizadores ${ }^{6}$.

En cuanto a una visión de la economía portuguesa en el marco de los países de la Europa del sur, son particularmente interesantes las ponencias presentadas en Sevilla, en un curso de la Universidad Internacional Menéndez y Pelayo (1984) y el trabajo de Gabriel Tortella (1984).

Los problemas de periodización siempre esconden grandes cuestiones teóricas. De ahí el interés de las escasas cronologías existentes (L. de Azevedo, Violante y Morais). Lo mismo podemos decir de los estudios sobre historiografía, de V. M. Godinho, J. V. Serrão y A. H. de Oliveira Marqués. En cuanto al pensamiento económico, en que fue pionero el profesor $\mathrm{M}$. Amzalak ${ }^{7}$, son muy escasos: entre los veteranos, Antonio Sergio y F. P. Loureiro, y recientes, Armando Castro $(1980 c)$ y Carlos Bastien (1984), sobre la Revista de Economía y la introducción del keynesianismo en Portugal ${ }^{8}$. Una serie reciente de trabajos sobre la crisis del Antiguo Régimen ha venido a ocuparse tanto de las estructuras de aquél (para el xvir, la excelente obra de A. M. Espanha, 1986; también C. A. Hanson, 1981) cuanto más exactamente de la economía del xviII (J. Borges de Macedo, 1951, 1963); fuentes básicas en Ch. Wilson y G. Parker (1985); una buena perspectiva para la historiografía reciente, Aurélio de Oliveira (1987), la estructura social (V. Magalhães Godinho, 1980) o la transición hacia el capitalismo (J. Serrão y G. Martíns, 1978). Este último asunto ha despertado, particularmente tras la revolución de 1974, una notable cantidad de trabajos, de muy desigual calidad e interés. Citemos los de V. M. Godinho (1970), J. Avelãs Nunes y otros (1971), R. da Costa (1975), Manuel Villaverde Cabral (1977), con

\footnotetext{
- Recordemos la breve polémica mantenida entre M. H. Pereira y Gabriel Tortella en esta revista (1983, III, 3, pp. 521-523 y 549-552), a propósito de la reseña que éste hizo del libro.

'M. Amzazak, Do Estudo e da Evolução das Doutrinas Económicas em Portugal, Lisboa, 1928.

- Por otra parte, acaba de aparecer un libro colectivo (AA. VV., 1988) que revisa am. pliamente la Historia del Pensamiento Económico. No he podido conocer la tesis, aún inédita, de José Luis Cardoso, sobre «O pensamento económico no final do século xviII e início do xix*, de que me habla M. H. Pereira.
} 
el que polemizaron, entre otros, Albert Silbert y Armando Castro (1979); Serrão y Martíns (1978), M. H. Pereira (1979 a, art. «Sobre la adecuación...»; 1979 b; 1983), Alfredo Marqués (1981), Vítor de Sá (1981), Valentim Alexandre (1986), Jobson Arruda (1986), Armando Castro (1987) y, muy destacadamente, Albert Silbert (1977), 1978, 1981).

\section{Los estudios demográticos}

La demografía histórica, que en Portugal apenas se destaca de la Historia Económica hacia rutas propias - lo que sí ocurre ya en casi toda Europa-, cuenta con notables trabajos de J. M. Nazareth $(1979,1983,1985)$ y uno de M. Livi Bacci (1971) sobre la fecundidad entre 1860 y 1960: «uno de los aspectos más interesantes de la demografía portuguesa es el relativamente bajo nivel de fecundidad anterior al comienzo del declive moderno, junto con la existencia, durante el mismo período, de diferencias sustanciales entre norte y sur" ${ }^{9}$. De ahí deduce ciertas reflexiones sobre las diversas actitudes populares respecto a las tradiciones, la autoridad, la vida familiar, las innovaciones, y el avance de la correlación posible con el comportamiento demográfico.

Una serie de trabajos demográfico-bistóricos (J. de S. Bettencourt, 1961; F. M. da Silva, 1970; J. Evangelista, 1971; Joel Serrão, 1973, 1974; Morgado, 1979; Arroteia, 1983, 1984, 1985; Barata, 1985; y varias monografías en el extra de Análise Social sobre el siglo xx) aportan documentación, comentarios y reflexiones ${ }^{10}$. M. H. Pereira $(1969,1981)$ estudia el crecimiento demográfico como factor del desarrollo económico y, a la vez, su resultante. Aunque critica las fuentes (hasta 1864, fecha del primer censo moderno, no hay datos fiables), acepta globalmente los del período 1835 . 1911, en que Portugal casi duplica su población, pasando de 3.061 .684 a 5.547 .708 , con una cierta mejoría en las condiciones de vida y una mayor longevidad (F. Sousa, 1979). Como es sabido, en los otros tres cuartos de siglo siguientes esa cifra vuelve casi a duplicarse, sobrepasando los diez millones.

El modelo «antiguo régimen» se mantiene hasta el último tercio del XIX, $y$ hasta entrado el $\mathbf{x x}$ se distinguen claramente tres regiones demográficas: la zona interior montañosa, de alta mortalidad y grandes oscilaciones; la zona de transición, con tasas más atenuadas, y la litoral, más bajas. Las ciudades de Lisboa y Oporto (ésta con mucha mayor mortalidad que la capital, será

- M. Livi Bacci (1971), p. 125.

10 Una tesis inédita, la de N. Araújo, estudia la historia demográfica de una localidad, Guimarães. 
llamada por su insalubridad «a cidade cemiterial portuguesa» por Ricardo Jorge) crecen en ese período muy por encima de las villas y aldeas ( 77 por 100 frente a 30 ó 22 por 100 en las parroquias rurales). De hecho, los principales núcleos industriales - Lisboa, Oporto, Aveiro y Setúbal- doblan su población entre 1864 y 1911, y casi también Covilhá. Aunque en esa última fecha la población activa dedicada a la agricultura es aún el 56,54 por 100 , la proporción baja con cierta rapidez, repartiendo los sectores industrial y de servicios casi por igual el resto".

En cuanto a la emigración, se le achaca el freno del nivel económico y el estancamiento de la segunda década del siglo $\mathrm{xx}$, a la vez que un claro envejecimiento general (V. M. Godinho, 1978; J. M. Nazareth, 1979; A. Leeds, 1983; E. Leeds, 1983; J. Serrão, 1985 b; Leite, 1987). El destino mayoritario es Brasil, a donde, gracias a las grandes facilidades gubernativas entre 1870 y los años 1920 , va el 87 por 100 del total migratorio. La emigración neta de Portugal entre 1886 y 1911 alcanza la cifra de 380.000 personas, la mayoría de las zonas rurales del norte y sur ${ }^{12}$.

La emigración -explica M. H. Pereira- además de dar salida a una mano de obra subempleada que la revolución liberal expulsaba del campo y el lento crecimiento industrial no permitía absorber, será un componente fundamental de la balanza de pagos, pese a lo cual la política de emigración fue siempre ambigua y hasta contradictoria, procurando, aunque sin manifestarlo abiertamente, mantener la corriente de divisas procedentes del Brasil, desplazar paulatinamente contingentes hacia Africa y conciliando todo ello con el mantenimiento de una abundante oferta de mano de obra para el campo y la industria.

En estrecha vinculación con este tema del "capital humano» está el de la educación, hoy estudiado ya desde esa perspectiva (Cervalho, 1986).

\section{AGRICULTURA, INDUSTRIA Y COMERCIO EXTERIOR}

\section{II.1. La agricultura}

Siendo Portugal un país eminentemente agrario, no abundaban los estudios de conjunto y en profundidad hasta hace muy poco. Como en otros casos, una temprana antología de textos de M. V. Cabral (1974) daría paso a algún estudio de conjunto (Coloquio de Aix-en-Provence, AA.VV. 1985) ${ }^{13}$

\footnotetext{
"Sobre la creciente urbanización, además del antiguo de Girão (1945), véanse los trabajos de J. Gentil da Silva (1979) y Vítor Matías Ferreira (1986).

${ }_{12}$ R. E. Poppino, Brazil, Nueva York, 1968, p. 193.

13 La tesis inédita de Maria Carlos Radich, «A agronomia portuguesa no século XIX», es un trabajo exhaustivo, cuya publicación aguardamos con interés.
} 
y diversas monografías. Así, los estudios sobre la evolución de la propiedad de la tierra (A. Silbert, 1970; L. E. da Silveira, 1980; H. A. Fonseca, 1983). El primero de ellos ha planteado la historia de la abolición del feudalismo (expresión que prefiere sustituir por economía señorial, según muchos de sus colegas franceses), asimilada a la de las «cartas forais». La jurisdicción señorial, aunque no del todo eliminada, fue duramente atacada en la ley de 1790 , correspondiendo a las luchas políticas de los años veinte y treinta del xIX su definitiva supresión, si bien la medida más decisiva es la ley de forales de 1846. Sin embargo, al expropiar las viejas concesiones perpetuas, se mantienen íntegros los derechos señoriales en los casos de arrendamiento, aparcería o explotación directa, lo que resulta claramente favorable a la gran propiedad. El peso del régimen señorial era mayor en el norte y centro que en el sur, donde seguirá predominando la gran propiedad (Barros, 1985), no afectándole apenas las transformaciones de la revolución liberal. Por otra parte, sobre todo en el centro y norte, las burguesías agrarias locales se interponen frecuentemente entre los señores y los explotadores directos, sacando mayor provecho. De ahí que Silbert evoque la fórmula de «revolução agrária abortada».

Son, en cambio, muy escasos los estudios sobre las ventas de bienes nacionales: de un primer momento (1834-43) en que se desamortizan bienes de la Iglesia, de la familia real y parte de los de la Corona, se pasa en los años sesenta a hacerlo sobre todo de los parroquiales, de beneficencia, enseñanza, municipales, etc., en un proceso muy semejante al español (Silveira, 1980).

En cuanto a la estructura social del campo portugués, interesantes monografías estudian una comunidad trasmontana (J. B. O'Neill, 1984), o la mentalidad de un agricultor alentejano (A. C. Matos y otros, 1982, con una estupenda introducción de Jaime Reis), o los estudios de H. A. Fonseca sobre empresarios (1984) o labradores (1985), o los de J. Cutilleiro (1977) sobre ambos grupos. La tesis de Rui Feijo (Oxford, 1984) estudia las relaciones entre revolución liberal, cambio social y desarrollo económico en la región de Viana en el siglo xIx. Las relaciones de producción (Carlos da Silva, 1979) se analizan en un reciente encuentro sobre «Agricultura latifundiaria na península Ibérica» (1980).

La estructura de la producción ha sido también recientemente planteada en perspectiva histórica (Baptista, 1985). Y sobre todo por Miriam Halpern Pereira, que estudia la producción agraria en el siglo xIx (1983) en su fundamental estudio «Livre-Câmbio e Desenvolvimento Económico» (1983 a), poniendo en relación disponibilidades demográficas (condicionantes y condicionadas) y crecimiento económico; analizando la extensión de tierras cultivadas, las modificaciones técnicas y el crecimiento del sector comercializado, 
así como la evolución de los precios. Entre otras constataciones, muestra cómo los cereales (maíz en primer lugar, trigo, centeno) ceden ante las mejores oportunidades del ganado y, en parte, las explotaciones forestales (especialmente el corcho).

En cuanto a las principales innovaciones técnicas (los abonos y la mecanización), que aumentan la productividad del trabajo agrícola, su implantación no sólo es atrasada, sino lenta e irregular ${ }^{14}$. Los cambios en los métodos de cultivo no son menos significativos (siembra, rotación, prados, etc.), así como la estabulación del ganado, etc., que aceleran las transformaciones de las reformas liberales. Sin embargo, el extremado y creciente minifundio del norte, y el latifundio del sur, serán dos formas opuestas de dificultar un proceso de modernización.

Es en ese sentido en el que, según las tesis de M. H. Pereira, la comercialización, al forzar la formación del sector capitalista de la agricultura, contribuye al crecimiento económico. Sectores como la seda, y, sobre todo, el vitivinícola, tienen una gran importancia, y eso que el Duero sufre una fuerte regresión al perder el lugar privilegiado del vino de Oporto en el mercado británico y padecer la filoxera ${ }^{15}$. Ni la transformación hacia el tabaco, ni las replantaciones, le devolverán el pasado esplendor, y la viticultura se expande ahora al centro y sur, de manera que casi la mitad de la producción saldrá de los distritos de Lisboa y Santarém, representando el 54 por 100 de su producción agrícola. Estudia también los precios de los principales productos (cereales, leña, carne, aceite, vino, etc.) en conexión con la diversa evolución por zonas de unos u otros cultivos, y la incidencia de la crisis agraria, y muestra la íntima relación entre las transformaciones agrarias y los movimientos de precios y, entre ambas magnitudes, las fluctuaciones comercia'es.

En ese período, la mayor parte de las mercancías exportadas provienen del sector agrario (el vino representa un tercio, a veces la mitad del valor total). De ahí que, tras la pérdida de Brasil y la gran crisis agropecuaria finisecular, «es la creación de un mercado colonial en Africa, lo que permitirá a Portugal recuperar el equilibrio y conservar una estructura económica arcaica, poco resistente a la competencia».

14 Reis (1982) es autor de un modélico estudio sobre el progreso técnico en el latifundio, analizando la implantación en el Alentejo de la trilladora mecánica, retrasada respecto a otros países, pero de rápido ritmo cuando se introduce en las primeras décadas del siglo Xx. Tanto el atraso como la adopción se deben a razones estrictamente económicas: el paso supone una alteración en los costos relativos de producción, el aumento de la escala de las explotaciones cerealistas $\mathrm{y}$, claro, también alteraciones de fondo en los terrenos técnico, económico y social. Otros trabajos modélicos son los de Veiga de Oliveira (1983, 1984), Fernando Galhano y Benxamin Pereira, sobre las formas de trabajo en el mundo rural.

is Véase D. W. Morrow (1973), sobre la incidencia de la filoxera. 
M. H. Pereira, ante ese Portugal que ocupa un lugar típico de país dependiente (exportador de materias primas y productos agrícolas, recibe materias primas industriales como el algodón o maquinaria), confirmando «el papel contradictorio que los mercados exteriores, simultáneamente factor de progreso y de atraso, desempeñan en el desarrollo del país», se pregunta: "¿A qué conduce la política de libre-cambio? Portugal se volverá durante cerca de cuarenta años "una vasta granja para la exportación"... Un único país, la Gran Bretaña, absorbe del 50 al 60 por 100 del total del comercio exterior: es el principal mercado consumidor y abastecedor de Portugal. $\mathrm{Si}$ el sector industrial es vivamente perjudicado por esta situación casi colonial, la agricultura, por el contrario, se beneficia nítidamente de la existencia de un vasto mercado exterior, rico y relativamente estable... La extensión del comercio agrícola provoca la extensión del sector comercializado de la agricultura... La localización geográfica de los centros sericícolas, de los centros de producción y cría del ganado, o de las regiones arrastradas por la fiebre vitícola de los años de 1880-1889, testimonian que nuevas zonas se van integrando... El período de la Regeneración no puede, pues, ser considerado en modo alguno como de estancamiento del sector agrícola... Sin embargo, la desigualdad del crecimiento de los sectores agrícola e industrial acaba por dificultar el propio desarrollo agrícola y por frenar el conjunto de la economía nacionals ${ }^{16}$.

El fin del librecambismo ha sido descrito por Jaime Reis (1980), que estudia el granero portugués del Alentejo, y muestra cómo en 1889 , en la cresta de la crisis agropecuaria europea, se adopta sin vacilación un régimen firmemente proteccionista (la célebre «Lei da Fome»), que se prolongará durante el salazarismo en un período más largo que en cualquier otro país y asumiendo algunas formas inéditas, que harán que la crisis tenga quizá menor incidencia en la agricultura portuguesa. Pero, en todo caso, es preciso insistir en que el aparato proteccionista benefició principalmente a los grandes propietarios del sur y, en particular, del Alentejo. De todos modos, llama la atención que la larga tradición de hipersensibilidad popular por el precio del pan consigue mantenerlo en niveles muy por debajo de otras subsistencias, y constante entre 1879 y 1909.

Por su parte, Pedro Laíns (1987 a) ha establecido el indice del producto agricola portugués entre 1845-1913, a partir de varias series de producción de cereales, productos animales y vinos, agregando sus valores finales. De ahí deduce una etapa de estancamiento (subdividida en una de regresión, 1852-61, y otra de recuperación, 1861-74) que será seguida de otra de crecimiento relativamente acentuado entre 1879 y 1900 , para volver al estancamiento,

\footnotetext{
${ }^{16}$ M. H. Pereira (1983 a, 2." ed.), pp. 315-321.
} 
seguramente debido al aumento extensivo y no intensivo de la producción, sin alterar los procesos de producción ni los niveles de inversión.

En relación con la producción agraria, no podemos olvidar el complejo asunto de los precios. Dos obras clásicas: la de Albert Silbert sobre los precios de los cereales en Lisboa de mediados del xviII a mediados del xIX (1970) y la de V. M. Godinho (1955) para el siglo siguiente. M. H. Pereira (1975) ha estudiado los niveles de consumo y niveles de vida (1874-1922). Ferreira, Pinto y Amorín han construido unas series para el mercado de Oporto en la segunda mitad del xIX (1972), David Justino para el de Aveiro (1978) y Carlos Pimenta ha vuelto sobre salarios y precios en el XIX portugués (1983).

\section{II.2. La industrialización}

La reciente historiografía económica portuguesa ha seguido los pasos, si no siempre el método, de Jordi Nadal para España en su pregunta por «el fracaso de la industrialización». A estudios clásicos, bien para los orígenes (J. B. de Macedo, 1963) o para el xIX, como los de Armando Castro (1978), y Joel Serrão (1977, 1979), la antología de Serrão y Martíns (1978), o Santana (1984), se han unido otros planteamientos (Bonifacio, Mendes, ambos de 1980) que vinculan el desarrollo industrial a la competencia extranjera. Por su parte, Pedreira (1987) ha rechazado la tradicional explicación sobre la coyuntura posterior a la invasión francesa: la verdadera causa del atraso en esos años estaría en aspectos estructurales (económicos y sociales), desde la estrechez del mercado interior hasta la poco decisiva acción del Estado.

Joel Serrão (1979) ha planteado el estudio «de las razones históricas de los fracasos industriales portugueses», vinculando, de una parte, como ya hiciera Oliveira Martíns un siglo antes, al imperio colonial toda la vida económica nacional, y señalando una periodización de las diversas tentativas de industrialización: una primera, a fines del xvir, de arranque, de estímulo oficial a las fábricas de tejidos de lana; una segunda, un siglo después, en el período pombalino; una tercera $(1812-26)$, intento de creación de manufacturas para el mercado interior; una cuarta (1835-50), tras la guerra civil (regeneração, fontismo, etc.); y una última, de 1855 a 1914, en que el capitalismo prefiere seguir, lo mismo que hará en la I República, apostando por la agricultura y por Africa, que lanzarse al desarrollo industrial. Para Serrāo, las condiciones institucionales del atraso industrial portugués vendrían dadas por: 1) las precedentes realidades políticas, vinculadas al proyecto y la conservación del Imperio brasileño; 2) la específica red comercial alimentada en ese sentido, dejando las relaciones con Europa en manos ex- 
tranjeras; 3) que en coyunturas comerciales desfavorables, el Estado se ve forzado a definir, voluntariamente, una política industrial, sólo eficaz sectorial o regionalmente.

Tras la pérdida de Brasil, se busca una salida capitalista, en la que faltan capitales «innovadores» y —añade Serrão- el librecambismo impuesto por Inglaterra fuerza a ruralizarse. Pero tampoco ello se hace con rasgos capitalistas. De modo que la crisis comercial-agrícola de los años 1870 se transformará en crisis nacional. A ello, finalmente, añade una serie de «trabas espirituales» al desarrollo industrial: la dominación aristocrática hasta, al menos, la victoria liberal de 1834; el dominio de los valores culturales y actitudes mentales aristocrático-clericales; el lento progreso del status burgués, en la segunda mitad del xix: la lógica de ese sistema no necesitaba progresos en la agricultura, sino mantener la riqueza...

Jaime Reis publicó, en 1986, una cuidada síntesis del proceso industrializador portugués entre 1870 y 1913, enmarcando dicho proceso en un cambio económico a menudo aludido como la «difusión del capitalismo», que «comportaba una ampliación del mercado, una creciente división del trabajo, el desarrollo de una moderna red de transportes, la emergencia de un sistema bancario y la utilización de técnicas modernas por parte de algunos sectores». Frente a las posiciones encontradas de Castro y Cabral, que creen que hubo una industrialización vigorosa y prolongada, y $\mathrm{M}$. H. Pereira, que lo niega y habla incluso de «desindustrialización» para 1870-91, adelanta J. Reis un primer índice de producción industrial (1985) para el período 1870-1913, a base de las industrias del algodón, lana, lino, tabaco, productos alimenticios, papel, azúcar, conservas de pescado, productos metálicos y minerales. Pues bien, aunque los resultados son inferiores a los presentados por M. V. Cabral, la tasa de crecimiento industrial, entre 2,5 y 2,8 por 100 anual no es nada despreciable, y no mucho menor que la de otros países europeos, si bien demasiado baja para un país atrasado. Pero era una tasa muy por encima de la agrícola, con lo que se cae por su base el tópico de que la agricultura fue, tras 1870 , el sector dinámico de la economía. De todos modos, el desarrollo industrial habría sido más vigoroso antes de 1891 .

Algunas monografías permiten acercarse en profundidad a determinadas áreas sectoriales; así, la de Vasco Pulido Valente (1982) sobre la industria conservera de Setúbal. J. M. Amado Mendes (1980) ha trabajado sobre las relaciones entre la industria portuguesa y las extranjeras, destacando la tentativa de arranque a finales del siglo xIx en la industria textil algodonera, debido a la protección arancelaria y al mercado colonial; la competencia de otros países (Alemania, Francia, Estados Unidos, España) a Gran Bretaña, como importadores y como inversores; los intentos de atenuar el desfase tecnológico con la creación de escuelas industriales y el envío de comisiones 
y estudiantes al extranjero. Es autor también (1984) de una destacada monografía de historia regional ${ }^{17}$.

\section{II.3. El comercio exterior}

Es éste uno de los capítulos más apasionadamente planteados en los últimos años. No en vano el comercio exterior es el gran capítulo de la Historia económica portuguesa, desde los clásicos G. Pery (de fines del XIX, reed. en 1979), Shillington y Chapman (1907). La obsesión por la dominación inglesa y la dependencia así generada, ha dado lugar" a trabajos como los de Sandro Sideri $(1961,1978)$, H. E. S. Fisher (1969), Armando Castro (1974), M. H. Pereira (1974, 1983, 1987) y M. ${ }^{a}$ Fátima Bonifacio (1987). Fisher (1969) ha destacado la importancia del comercio portugués para Inglaterra: «Durante la primera mitad del siglo xviri, y tras el comercio colonial angloamericano en su conjunto, Portugal representó el mejor mercado para las manufacturas inglesas en virtud, esencialmente, del atraso económico portugués y de la creciente prosperidad brasileña, en la que los metales preciosos tenían un papel tan importante. Probablemente las relaciones comerciales estaban cambiando en favor de Portugal desde 1715 hasta 1750 ", aun cuando esta tendencia se invierte a partir, sobre todo, de 1760 . Es la época de Pombal, en que los aranceles aumentan para proteger las propias manufacturas, a la vez que se crean y potencian reales fábricas.

En el mismo sentido se manifiesta Armando Castro (1974) en una amplia introducción a varios textos de época, aunque advirtiendo que a la sazón se ignora aún la dimensión del dominio económico británico en Portugal en los siglos xviII y xix, lo que no le impide valorar, ante un cuadro sobre los déficits de la balanza de pagos con Gran Bretaña y el porcentaje de los mismos respecto al saldo mundial (que en el período 1701-1764 alcanza una máxima del 42,7 por 100 en 1738-39, aunque otros muchos años apenas pasa del 20 por 100 ), que el mercado portugués (por supuesto, incluyendo entonces Brasil), «constituyó, indiscutiblemente, un elemento fundamental de la expansión del capitalismo británico en gestación y progreso».

También Sandro Sideri (1978) estima que la división internacional del trabajo entre Portugal e Inglaterra procede de los tres tratados del siglo XviI (1642, 1654 y 1661) y del célebre de Methuen (1703), de un claro efecto desfavorable para la economía portuguesa, que equilibra el déficit durante todo el siglo con el oro brasileño. Estima también que las tentativas de fines

17 No entramos en detalle sobre estudios dedicados a fábricas concretas, etc., de los que pueden contarse un par de docenas, algunos de gran interés. 
del xviri para industrializar Portugal se ven frustradas por acontecimientos exteriores, fundamentalmente la pérdida colonial y las invasiones napoleónicas ${ }^{18}$; y que luego falla la diversificación de la economía, mientras crece rápidamente la deuda exterior con el intento de establecer las colonias africanas, que tardan en sustituir el mercado colonial americano.

La importancia del Brasil en la economía portuguesa ha sido destacada por F. Mauro (1970) y C. R. Boxer (1969), J. Capela (1977), V. Alexandre (1979), M. B. N. Silva (1986), y de su pérdida, por Joaquín del Moral Ruiz (1979), J. A. Arruda (1986) y Valentim Alexandre (1986). Este último califica de dramáticos los efectos económicos de la pérdida del Imperio brasileño. Por una parte, Portugal es sustituido por Gran Bretaña en Brasil, como principal proveedor y cliente, perdiendo un gran mercado protegido, con lo que, «con el colapso del comercio de productos coloniales desaparece una de las principales fuentes de acumulación de capital, afectando duramente a la burguesía mercantil de la plaza de Lisboa, tanto portuguesa como extranjera», así como a la de Oporto. Los envíos a Brasil se reducen a la tercera parte, apenas destacando el vino; también se pierde la condición de intermediario. Según Sideri (1978), como resultado de la pérdida del Brasil las exportaciones e importaciones portuguesas en su conjunto disminuyeron en más de la mitad entre 1816 y 1855 , sin que se redujese el déficit comercial total: a partir de 1819 el déficit nunca fue menor del 10 por 100 del total del comercio exterior.

(Esa pérdida intentará ser compensada tiempos después con el nuevo imperio en Africa, de cuyo estudio se han ocupado R. J. Hammond, 1966; J. Capela, 1972, 1975; A. Castro, 1980 a; A. Guimarães, 1983; M. H. Cunha Rato, 1983, y, sobre todo, Gervase Clarence Smith, 1985. El análisis de este tema desbordaría este informe ya demasiado extenso.)

Uno de los aspectos más tópicos del comercio portugués es el de la polémica proteccionismo-librecambismo, ya mencionado en las citas a $\mathrm{M}$. $\mathrm{H}$. Pereira ${ }^{19}$, J. Reis y Pedro Laíns. Digamos simplemente al respecto que el debate debería colocarse no tanto en el librecambio anterior a la crisis agraria finisecular (no suficiente, según Reis y Laíns), cuanto en lo inevitable del proteccionismo posterior. En efecto, la discusión sobre el modelo proteccionista a partir de los años 80 carece de sentido: Portugal se ve abocado al cierre defensivo. Sin embargo, hay que destacar la eficacia del proteccionismo, al preparar un «tejido industrial» capaz de incorporar sucesivos cam-

1s Véase J. Borges de Macedo (1962).

29 Añadimos, en prensa, su artículo (1988), en que, refiriéndose al tratado de 1810 con Inglaterra, insiste: "Toda la futura estructura económica iría a quedar marcada por el bloqueo resultante del mantenimiento de este desastroso acuerdo, que acabó por durar veintiséis años en lugar de los previstos quince» (p. 233). 
bios posteriores ${ }^{20}$. P. Laíns $(1987 b)$ plantea, por su parte, un mentís rotundo a las tesis sobre el librecambismo: entre 1842 y 1913, según Laíns, la práctica habitual fue fuertemente proteccionista, beneficiando economías escasamente competitivas y el ingreso arancelario para la Hacienda ${ }^{21}$.

En cuanto a la segunda mitad del XIX, estudiada por Miriam Halpern Pereira (1983), el comercio exterior portugués sufre alteraciones decisivas en su composición y dirección: aumenta la exportación de corcho y conservas de pescado, continúa el papel importante del vino, pero también la entrada de máquinas (siempre pocas) o algodón. Una típica situación de «intercambio desigual», agravada cuando, a fines de los 80 , Inglaterra y Francia dejen de adquirir el vino y otros productos agrícolas, desapareciendo prácticamente el mercado tradicional, que deberá ser reemplazado por el colonial ${ }^{22}$. De interés son también estudios monográficos como el de J. B. Beviano (1960) sobre el papel comercial del puerto de Lisboa; de M. F. Alegría, sobre la organización portuaria en general (1985), y de M. F. Bonifacio, sobre el comercio de Oporto $(1986)^{23}$.

\section{II.4. El debate sobre el atraso económico portugués}

Jaime Reis, como ya hemos visto, estudia la producción industrial portuguesa, 1870-1914 (1985), estableciendo una serie de análisis $(1984,1986)$. En el primero de ellos plantea un gran debate que revisa profundamente la historiografía más reciente sobre las razones del atraso portugués. Un atraso fuera de duda: en 1913 la distancia que separa a Portugal de los países más desarrollados en cuanto a PNB per capita es probablemente mayor que nunca hasta entonces, mientras que a mediados del xIx, salvo con Inglaterra, esa distancia era mucho menor, y a pesar del espectacular desarrollo de los grandes países industriales a lo largo de este siglo, la proporción de 1913 apenas ha descendido ${ }^{24}$.

20 Un reciente trabajo de M.' Fátima Bonifacio (1987) aclara cómo alas diversas $16-$ gicas (políticas y económicas) de la política arancelaria adoptada en la primera mitad del siglo xix explican la convergencia de puntos de vista entre el Estado y los intereses privados respecto a la imposición de derechos arancelarios elevados». Advierte, sin embargo, de que la única oposición seria no tiene contenido de clase, sino regional: proviene de los grandes exportadores de vino de Oporto, enfrentados a partir de 1840 con una grave crisis, por excesiva acumulación de stocks.

${ }^{21}$ De hecho, como ha estudiado también M: Fátima Bonifacio (1984), el tratado de 1842 no supuso un acuerdo de reducción de derechos arancelarios, pues remitía a futuras negociaciones que no se llevaron a cabo.

${ }_{22}$ M. H. Pereira (1983 a, 2.: ed.), pp. 281-283.

${ }^{23}$ No he alcanzado a ver el trabajo de Sacuntala de Miranda, «O declínio da supremacia inglesa, 1890-1939*.

${ }^{24}$ Armando Castro, en un viejo trabajo reeditado en 1978, presentaba los datos (muy 
Sintetiza Reis las tres principales tesis sobre el atraso portugués: Sideri y Pereira lo atribuyen a la dependencia externa de Inglaterra; Pereira y otros, al atraso agrícola, tanto en la estructura de la propiedad tras las reformas liberales cuanto a la escasa demanda y formación de capital inversor; Serrão-Martíns, Godinho y, desde otra perspectiva, M. V. Cabral, a las estructuras sociales y mentales de la época y al Estado que, «dominado por la burguesía asociada al import-export beneficiaria de la dependencia exterior, no proporciona un marco legal e institucional propicio al desarrollo económico». Estas tesis no son incompatibles y ofrecen sugestivos planteamientos ${ }^{25}$; si son rebatidas es como argumentos excluyentes: difícilmente puede argumentarse sobre la dependencia exterior, cuando a fines de siglo las exportaciones apenas representan el 7,5 por 100 del PNB, poco más de la mitad de la media europea, y las exportaciones crecen a una tasa anual de apenas el 1,2 por 100 anual. (Claro que la única virtud de la exportación no es cuantitativa, pues ese pequeño margen tiene su eficacia y permite obtener precios remuneradores en el interior, etc.) La dependencia, además, era dificultada por un notable proteccionismo (según Bairoch las tarifas portuguesas en 1875 ó 1895 eran de las más altas de Europa).

La tesis de la estructura agraria - que le parece más en razón a Reistiene el inconveniente de su escasa posibilidad de cuantificación y los contrafactuales que precisa. Sobre la mentalidad atrasada está de acuerdo en que oprimen aún a la sociedad de 1900 la ignorancia, el analfabetismo, la falta de cualificación de la mano de obra. En definitiva, la deficiencia de capital humano «era una dificultad estructural cuya superación tendría un elevado coste y sólo se podría realizar al cabo de una o más generaciones».

De ahí que Jaime Reis responda con una argumentación provocadora, a contracorriente de casi toda la historiografía portuguesa: «en vez de afirmar

incompletos) del atraso técnico según la encuesta industrial de 1881 y su evolución en los decenios siguientes: la fuerza de vapor disponible era de $6.972 \mathrm{HP}$. A principios del siglo $\mathrm{xx}$, la potencia era de $110.000 \mathrm{HP}$, de los que apenas el 5 por 100 generado por industrias eléctricas. Otro dato importante es el consumo de hulla, que pasa de 614.688 toneladas en 1896 a 1.200 .000 en 1915 . En 1875 había en la industria algodonera 50.000 husos y 400 telares mecánicos; cinco años después, 108.000 husos y 1.000 telares, y en $1899,230.000$ husos, a pesar de lo cual se seguian importando, en 1880,165 toneladas de algodón torcido, 41 de algodón en hilo, 144 de tejidos crudos, 1.662 de tejidos blanqueados y 130 de tejidos teñidos o estampados. El valor total de lo importado ese año en materias primas ( 10 millones de pesos) se triplica en 1913.

${ }_{23}$ Poco después, el propio Reis (1986) resumía así los factores principales del «retrasow: 1) la pérdida de las colonias, la devastación de las invasiones napoleónicas y la guerra civil; 2) la competencia extranjera consentida por tarifas arancelarias demasiado bajas; 3) lo limitado del mercado nacional, basado en una agricultura atrasada; 4)' la debilidad y las divisiones de una burguesía incapaz de utilizar el poder del Estado a su servicio; 5) la escasez de capitales, sobre todo para la industria; 6) una grave carencia de instrucción, técnica o elemental. 
que la débil industrialización resultó del bajo nivel arancelario, sería mejor decir que, a pesar de ser ese nivel elevado, eso no bastó para estimular el desarrollo de las manufacturas en gran escala». Además - añade-, hasta ahora se han despreciado factores como la dotación de recursos naturales, la dimensión de la economía, su localización geográfica y la configuración del mercado internacional, y todo ello, junto a los esquemas analíticos clásicos y a una adecuada jerarquización, puede ayudar a entender mejor esa debatida cuestión.

Para ello plantea tres contrafactuales, alterando uno o dos parámetros en diversos argumentos y estableciendo la situación resultante. El primero, sobre la tesis dependentista: en 1900 «las oportunidades para elevar el PNB a través de una industrialización vigorosa, volcada simplemente hacia el mercado interno, eran limitadas, a lo máximo, a un 2 por 100 del PNB..., aunque hubiese habido una enorme protección e incentivos estatales, un empresariado más orientado hacia las manufacturas y una mayar disponibilidad de capital industrial, el desarrollo económico estaba seriamente dificultado de partida por la deficiente dotación de recursos naturales, por un lado, y, por otro, por la debilidad de la demanda interior».

El segundo contrafactual se refiere a dos sectores (el del corcho y el conservero) con fuerte vocación exportadora, preguntándose en qué medida su mayor expansión - si no hubiesen escaseado capital y empresariado capaces- hubiera liderado el crecimiento general de la economía portuguesa de fines del xIx. Concluye, igualmente, que aunque el proceso del corcho se hubiera ultimado en Portugal, la ganancia no hubiera pasado del 0,35 por 100 del PNB; y que la situación de la industria conservera era de crisis continua, por la inelasticidad de la demanda exterior. De manera que no es, pues, la ausencia de una política de fomento o de talento empresarial lo que a juicio de Reis explica ese atraso. Por el contrario, se pregunta: «Dada la débil dependencia exterior de nuestra economía, en un periodo en que había importantes ganancias a obtener de una estrecha vinculación al comercio internacional, ¿no hubiera sido mejor una mayor dependencia exterior, aun privilegiando así la producción de materias primas? Por ejemplo, en un sector privilegiado, el vinícola, parece que se hubiera incrementado el PNB en al menos un 15 por 100 . Este era, con mucho, el camino más prometedor a la altura de 1900 », y «la solución más fácil para elevar el rendimiento real per capita hubiera sido acentuar la "dependencia exterior" y dejar que el fortalecimiento de la demanda interior estimulase la diversificación y luego el crecimiento, tal como sucedía en otros puntos de Europa». Pero el sector vinícola era uno de los menos expansivos y la demanda muy poco elástica, por la competencia internacional y la superproducción generalizada, además de la baja calidad del vino común portugués. 
Todo ello lleva a Reis a concluir que si en 1900 Portugal estaba hundido en el atraso económico, la situación difícilmente hubiera podido ser otra, y que «la dependencia o la inserción en la economía internacional, lejos de excesiva, no alcanzó el nivel adecuado para producir, de forma mantenida e intensa, el desarrollom. Esta brillante exposición ha sido uno de los principales motores de discusión y trabajo en la actual historiografía económica portuguesa.

Por otra parte -como veremos ha demostrado P. Laíns-, en esos años apenas crecen las exportaciones, lo que echa también por tierra que las exportaciones de materias primas, estimulando la demanda interna, hubieran generado el crecimiento de la industria. Reis cree qu ello se debió a la inelasticidad de la oferta, incapaz de traducir un incremento de la demanda en un inmediato aumento de la producción medida a precios constantes. (Parece olvidarse que, por muy elástica que hubiera sido la oferta, se hubiera encontrado con una serie de contradicciones: las condiciones sociales, la explotación de un recurso aquí escaso y abundantísimo en otros continentes, la crisis agraria de los ochenta, que hacía inviable el modelo librecambista mucho antes de fines del siglo.) Se constatan, además, relaciones entre las fluctuaciones de la producción industrial y las del mercado monetario, o los ciclos internacionales.

La otra gran pregunta: ¿por qué, partiendo de tal atraso, el desarrollo no fue más pronunciado? No resuelve mucho achacarlo a la débil burguesía nacional, ni es difícil citar factores como lo limitado del mercado interior, la escasez de mano obra cualificada y el elevado coste del capital. Por otra parte, el papel del Estado es muy modesto, falta un tipo de banco industrial y escasean capitales específicamente importados hacia la industria. Algunas industrias crecen muy despacio, en parte por la dependencia de materias primas de importación mayoritaria (el sector algodonero o el mecánico importan alrededor del $45-55$ por 100 del valor de la producción bruta). Además, la escasa intersectorialidad restó oportunidad de expansión al sector de la maquinaria de producción nacional. Y una paradoja: la sustitución de importaciones había sido muy temprana: hacia 1890 las importaciones de productos textiles, vestidos, alimentos, material de construcción, zapatos, etc., son ya porcentualmente muy bajas, por lo que es difícil crecer en los años siguientes. En cuanto a las nuevas colonias, apenas pueden absorber aún la producción de la metrópoli, por lo que sólo una mayor capacidad exportadora hubiera permitido el crecimiento de la producción industrial.

Frente a la desventaja de la necesaria importación de materias primas, dificultades crediticias o ineficiencia de las nuevas industrias, Portugal contaba con una ventaja clara en el bajo coste de la mano de obra que además suponía un alto porcentaje de los costes totales. Pero su productividad era 
muy baja, también lastrada por la escasa dotación de capital. Y a ello se añade - viene a concluir J. Reis - la falta de una red de transportes desarrollada y plenamente utilizada, o una extensa gama de servicios auxiliares como talleres de reparaciones o producción de piezas de recambio.

También los trabajos de Pedro Lains sobre comercio exterior (1986 e inédito) han supuesto un vuelco en los planteamientos tradicionales. La tesis de la dependencia ${ }^{26}$ es, revisada, en el sentido de que «la economía portuguesa se hubiera beneficiado de un crecimiento todavía mayor del sector agrícola de exportación a lo largo de la segunda mitad del XIX y que ese crecimiento se hubiera podido sustentar, al menos hasta la primera guerra mundial, sin haberse dado la fuerte recesión a partir de 1886. El argumento se basa en la constatación de que la demanda en el mercado mundial de productos alimenticios (incluyendo aquellos en que Portugal estaba o podría estar especializado), creció de forma satisfactoria entre 1850 y 1913 y en el presupuesto de que el crecimiento del sector agrícola - sobre todo de las industrias de transformación de productos de la agricultura- sería la mejor forma de sacar partido de los recursos de la economía portuguesa, teniendo en cuenta la coyuntura de la economía mundial de las seis décadas hasta 1913 " $n$. Ese desfase entre la oferta portuguesa y la demanda mundial resulta de una diferencia estructural: el aumento de la demanda británica, asociado a su aumento de renta nacional, se dirige a productos como trigo, carne y ganado para sacrificar, lacticinios y huevos (Portugal exporta sólo en notable cantidad el ganado bovino), y en cuanto a materias primas industriales, maderas, aceites minerales, caucho o pasta para papel (tampoco nada abundantes en Portugal). En todo caso, el problema estaba más en la estructura de la oferta (resultado inevitable de la reducida dimensión del mercado interno), que en los cambios de la demanda exterior inglesa, más desfavorable que la evolución general mundial.

El otro argumento ofrecido por Pedro Laíns (1985) se refiere a las dimensiones del sector exterior, que niega representara una parte significativa del producto nacional agrícola y, por lo tanto, del total. Si ese sector, dependiente de la economía mundial, hubiera evolucionado positivamente en su productividad exportadora, la dependencia hubiera sido aún mayor... y «esta situación hubiera podido servir de estímulo para el desarrollo y la modernización del sector exportador, con vistas a la satisfacción de mercados cada vez más exigentes, basados en el aprovechamiento del capital y de la capacidad empresarial tanto nacionales como extranjeros».

“ No sólo - aunque fundamentalmente- mantenida, como hemos visto, por M. H. Pereira. Véase también, por ejemplo, el artículo de Urs von der Mühll (1982).

" P. Lains (1986), p. 382. 


\section{OTROS TEMAS: TRANSPORTES, HACIENDA PUBLICA, SISTEMA MONETARIO, BANCA}

\section{III.1. Los transportes}

Los transportes, tanto en el conjunto de Portugal y sus islas (Matos, 1980) cuanto en el plano estrictamente continental, por carretera o ferrocarril (diversos estudios de A. Lópes Vieira), cuentan aún con escasos trabajos. No hemos podido conocer la tesis doctoral de Lópes Vieira (Leicester, 1983), aunque sí algunos trabajos de ella derivados (1981, $1982 a$ y $b$, 1984). Algo parecido nos ocurre con los de M. ${ }^{2}$ Fernanda Alegría $(1983,1987)$.

Nuestra información sobre el ferrocarril proviene sobre todo de los trabajos de Magda Pinheiro, que defendió su tesis doctoral, referida a ese asunto, en la Universidad de París I, bajo la dirección de Jean Bouvier (1987 a). En el primero de ellos (1979), insiste Pinheiro en la dependencia exterior -constitución de empresas extranjeras, financiación estatal a través de la deuda exterior, tipo de crecimiento económico-, y en lo espectacular y dispendioso de su construcción, que provoca caídas de gobiernos, presiones internacionales, etc.

Tras el fracaso del intento de construir la red con capitales nacionales (Companhia das Obras Públicas) y otros varios problemas, es entre 1859 y 1866 cuando son rápidamente construidas, con capital francés, las líneas Norte y Este, que enlazan Lisboa con Vila Nova de Gaia y Badajoz. En la etapa siguiente, hasta 1881, es el Estado el principal financiador, a través del déficit exterior (en 1879 la red estatal supone el 50 por 100 del total construido), volviendo a ser capital francés y alemán -aunque dirigido por portugueses- el predominante, y lográndose un considerable aumento de la red, aunque con final catastrófico en la mayor crisis empresarial y social del siglo.

En su tesis, de la que conocemos un capítulo sobre los ferrocarriles portugueses y su relación con España (1987 b), nos recuerda Magda Pinheiro que, frente al carácter nacional de la red de carreteras planeada en 1841, al ferrocarril se le atribuía la misión de asegurar una buena inserción de Portugal en la Península Ibérica y en Europa, convirtiendo a Lisboa en el puerto de Europa hacia América. La propuesta de creación de un mercado ibérico, una especie de "Zollverein» peninsular, provocará numerosos recelos políticos hacia España. Diversos problemas retrasan una línea lateral, OportoVigo, condicionada a la realización de la Lisboa-Madrid, por Badajoz, concluida en 1866, siendo menos urgente para los portugueses el ramal de Cáceres (1880) que el de Salamanca (1886).

La importancia de las líneas internacionales tiene, para M. Pinheiro, dos 
perspectivas: las relaciones comerciales luso-españolas y el tránsito hacia Europa. En las primeras, nos muestra la sorpresa de que apenas aumentan en las décadas siguientes, incluso decrece su porcentaje sobre el total del comercio exterior portugués (del 7 al 6 por 100). El ferrocarril no puede superar lo exiguo de nuestras relaciones económicas, y el menor precio final de otros trigos y harinas (americanos, sobre todo, que irán a Portugal por mar) que los españoles, a pesar de su cercanía. En cuanto al trásito de mercancías, que sólo interesa a la burguesía comercial, las compañías ferroviarias y marítimas tienen una gran influencia sobre las decisiones al respecto. Entre esas operaciones (reexportaciones, etc.) destacan los minerales procedentes de España (mercurio, especialmente) y los fosfatos, pero España, a partir de 1888, deja de tener importancia entre los países de origen (1,7 por 100 del total), mientras que es destino casi exclusivo (98 por 100) del total de las mercancías en tránsito. De los pasajeros casi no vale la pena hablar: no llegan, en los años 80 del pasado siglo, a 200 diarios.

Otro trabajo en esa línea es el de María Fernanda Alegría (1983).

\section{III.2. La Hacienda Pública}

Son bastante recientes los estudios sobre la política económica. De 1981 datan los de J. del Moral Ruiz sobre la Hacienda en la crisis del Antiguo Régimen, y de A. Castro sobre la primera mitad del xix. Señala el primero de ellos cómo el derrumbe de la Hacienda y el aumento de la Deuda Pública desde fines del xvin precipitan el final del Antiguo Régimen, y cómo la política desamortizadora, que comienza ya durante el cartismo y miguelismo, tiene sobre sí, en la época liberal a partir de 1834, la problemática hacendística. Para A. Castro, la Hacienda pública tuvo en la primera mitad del siglo xIx una función de redistribución de la renta nacional en beneficio de las clases privilegiadas. Mencionemos también un interesante panorama de Nuno Valerio sobre el papel del Gobierno en el crecimiento económico entre 1851 y 1939 (1986a). Según sus estudios, resulta ser mayor el porcentaje de crecimiento del PNB real per capita en la época de «transición» (18911913) y en el "Estado Novo" que en la época de la Regeneración, y en la I República, en que quizá los efectos de su política fueron más lentos de lo esperado.

Magda Pinheiro ha reflexionado sobre las finanzas públicas a lo largo del XIx (1983); L. E. da Silveira (1987), sobre el primer cuarto del siglo; $M{ }^{a}$ Eugenia Mata, sobre el cambio hacia el siglo xx (1985) y la importancia de la Deuda Pública (1986), complementada por N. Valerio, sobre la solvencia 
estatal (1986 b), y A. de S. Franco (1982), sobre el siglo xx en conjunto; Nuno Valerio (1982), sobre el período entre guerras, y también recientemente sobre el período $1913-83^{28}$. Recuerda M. Pinheiro cómo las rentas coloniales constituían una parte significativa de los ingresos del Estado, cuya pérdida supondrá un duro golpe, como bien entendió Mouzinho da Silveira. La crítica a la irracionalidad financiera del Estado absolutista genera una gran desconfianza en el gasto público; sin embargo, las funciones del Estado moderno no sólo impiden restricciones, sino que suponen cada vez mayores gastos. No basta el recurso a los bienes de la Corona y de la Iglesia, y se precisan grandes empréstitos extranjeros, que suponen un obstáculo al crecimiento económico. En cuanto a la posibilidad de una política fiscal que ahondara en el impuesto directo, lo que repercutiría en los grandes propietarios, está claro que «para los hombres de entonces, el Estado no debía alterar los equilibrios sociales existentes, sino garantizar la armonía»...

M. a Eugenia Mata sitúa la época entre la Regeneración y la Primera Guerra Mundial como momento de inicio de la estabilización de la Monarquía constitucional, en el que hay dos grandes reformas financieras que buscan la conversión de la deuda pública y la creación de una contribución territorial. Es el inicio de una fase «A» de Kondratieff. El modelo financiero de la Regeneración buscaba la reducción de los gastos tradicionales y el aumento de los ingresos, convirtiendo la deuda pública en 1852, intentando varias reformas fiscales, a la vez que se trata también de construir infraestructuras por inversión pública, con un elevado balance (cerca de $2.000 \mathrm{~km}$. de ferrocarril y otro tanto de carreteras, cerca de $8.000 \mathrm{~km}$. de telégrafo, faros, etc.). Era preciso «el fomento económico a través de los efectos de propulsión y arrastre sobre la agricultura y la industria por parte de la inversión pública», a la vez que «el equilibrio de las cuentas públicas a través del efecto de multiplicación de los ingresos del Estado por el crecimiento de la economía». Al menos lo segundo es considerado fallido por Mata para el período $1850-90$, mientras que entre 1890 y 1913 si se puede probar un crecimiento de la renta nacional de un 70 por 100 , lo que da un crecimiento real de cerca del 20 por 100 , si bien el crecimiento real por habitante fue prácticamente nulo. El modelo económico y financiero, que más que de la Regeneración es ya de la I República, está cambiando, y tiene como instrumentos la educación popular, la explotación racional de las colonias y el aumento de los ingresos y disminución de los gastos del Estado. Entre la bancarrota parcial de comienzos de los 90 y 1914, el éxito indiscutible radica, para esta autora, en el gradual paso hasta equilibrar el presupuesto, aumentando los gastos en educación y definiendo el dominio en Africa.

\footnotetext{
2* Valerio (1987).
} 
Por su parte, Nuno Valerio $(1982,1985)$ estudia en su tesis doctoral la situación de la Hacienda entre las dos guerras mundiales. Define los años 1914-24 como de crisis e inflación; 1924-29, de deflación, seguida de expansión en la autarquía, hasta la crisis, prosperidad e inflación de la época de la II Guerra Mundial. Destaca la actuación del Estado Novo, que sigue modelos muy tradicionales: invertir en infraestructuras, equilibrar el presupuesto, etc. De hecho, tras la gran depresión de 1929 , apenas se altera la política económica. Había la convicción de que la crisis se debía a anteriores prácticas inflacionistas; además, sus efectos fueron relativamente benignos; $y$, desde luego, se cree en la ortodoxia financiera practicada, llegándose en 1931 a plantear la paridad oro y libra con el escudo. Por otra parte, desde las primeras medidas en 1926, el nuevo régimen da marcha atrás en la dimensión del sector público, arrendando líneas férreas estatales, privatizando los tabacos, prohibiendo explotaciones comerciales o industriales por el Estado, aunque sí controlará la energía o regulará otros muchos aspectos y creará servicios autónomos.

En el artículo citado (1987), llega N. Valerio a una conclusión nítida sobre el papel de Salazar en la hacienda pública: «Desde el inicio de la Primera Guerra Mundial hasta hoy no hubo ningún año económico cuyas cuentas públicas cerrasen con saldo positivo cuando Salazar no estaba en el Gobierno, excepto uno: 1970. También está claro que la cobertura de los gastos por los ingresos fue, por lo general, muy inferior antes y después de pasar Salazar por el Gobierno que durante los años 1928 a 1968».

\section{III.3. La politica monetaria}

Aparte el clásico trabajo ya citado de V. M. Godinho (1955) y el de J. Gentil da Silva (1982), es preciso reseñar los de Nuvo Valerio (1984a) y M.a Eugenia Mata $(1984,1987)$. Establece Valerio una periodización que relaciona la moneda con la coyuntura económica; por ejemplo, también en el aspecto monetario se comporta positivamente la economía portuguesa en la gran depresión, manteniéndose como en el período anterior, aunque con mayor estabilización y crecimiento del PIB.

En cuanto a la política de cambios, M. ${ }^{a}$ Eugenia Mata señala las fluctuaciones a la baja entre 1891 y 1914, acentuándose el descenso vertiginosamente en la década siguiente, hasta alcanzar niveles treinta veces por debajo. Entre 1924 y 1931 el cambio se estabiliza unas 25 veces por encima del anterior, fijándose la estabilización legal en 1931. Esta autora cree que los cambios se explican por la renta nacional per capita y el nivel de precios; 
no se pueden explicar por la circulación monetaria y la tasa de interés, y que desde luego no sirven las teorías de la balanza de pagos y la paridad del poder de compra, o la cuantitativa de la moneda y la de la paridad de remuneración del capital. Precisamente Jaime Reis (1988) acaba de establecer la evolución del stock monetario entre 1846 y 1914.

\section{III.4. El sistema bancario}

Apenas podemos reseñar dos breves estudios, de Valerio y Mata (1982) y de H. Caeiro Pereira (1985), sobre el Banco de Portugal. Resume este último los principales datos sobre esta institución, creada en 1846 al fundirse el Banco de Lisboa (1821) y la Companhia Confiança Nacional (1844) ${ }^{29}$. Desde el comienzo es banquero del Estado y la Caja General del Tesoro, siendo la deuda estatal creciente. Sometido en 1867 a la nueva ley de sociedades anónimas, en 1887 recibe la consagración oficial, que se plasmará en 1891 en el monopolio emisor de billetes - a cuya convertibilidad en oro se compromete-, bajo control oficial. Pero el Banco de Portugal tiene escasos medios para orientar la política monetaria y es poco competitivo ante los bancos comerciales, apenas sujetos a normas.

Valerio y Mata afirman que el Banco de Portugal no fue mal negocio, ni para los accionistas ni para el Estado, si bien tras la Primera Guerra Mundial y antes de 1931 la gran inflación reduce mucho los beneficios. «De cualquier forma, el Banco se presentaba al inicio de la gran depresión como una empresa sólida, poseedora de reservas considerables (del orden de los ocho millones de libras) y potencialmente lucrativa. En esa base se intentaría asentar la reforma monetaria de 1931 e iniciar claramente la transición de un banco emisor único a un banco central.» La reforma de 1931 (la nacionalización no se realiza hasta 1974, tras la Revolución) supone un mayor control estatal. Se crean las bases de un nuevo sistema monetario, fijando un techo al crecimiento de la circulación fiduciaria y estableciendo reglas de cobertura a la emisión de billetes, lo que tendió a estabilizar el valor del escudo. Se fija también un límite de circulación en 2.200 millones de escudos y se obliga al Banco a mantener una reserva de al menos el 30 por 100 de sus responsabilidades a la vista. La situación de la deuda, casi equivalente al total de billetes en circulación, era gravísima, y su regularización es uno de los más cantados éxitos de Salazar.

\footnotetext{
2 Véase Nuno Valerio (1984 b), sobre esta última.
} 


\section{LOS ESTUDIOS POR EPOCAS}

Además de esos panoramas más o menos generales, abundan estudios monográficos, en ocasiones de muy alta calidad, sobre períodos concretos. Señalemos los más destacados:

\section{IV.1. El siglo XIX}

Como visión de conjunto, son importantes los extras de Análise Social $(1980,1987)$. La mayor parte de los autores citados hacen referencia, por otra parte, a este siglo, destacando A. Castro, M. H. Pereira, M. V. Cabral, J. Reis, P. Laíns y D. Justino. Estudian las primeras reformas liberales de los años veinte Silbert, 1968; Santos, 1980; Monteiro, $1985^{30}$. Una revisión muy actualizada y crítica es la realizada en el primer semestre de 1988 en el Instituto de Ciências Sociais de Lisboa ${ }^{31}$.

Miriam Halpern Pereira $(1979 b, 1982,1983,1987)$ se ocupa del período, con abundantes monografías. En Revolución, finanzas... (1979 b) plantea las claves de la formación del Estado liberal, con funciones cada vez más amplias que exigen mayor recaudación y una máquina administrativa, para lo que lógicamente tropiezan con la vieja estructura social y el poder de la Iglesia. De ahí la supresión de la estructura señorial, y la larga serie de conflictos políticos y sociales que se suceden en los años 20 y 30 del siglo XIX: «Dos proyectos parcialmente opuestos atraviesan, pues, las revoluciones liberales; uno de ellos se asentaba en la disgregación de la estructura señorial en beneficio de los campesinos, y planteaba la posibilidad de un nuevo tipo de organización financiera del Estado, basado en una tributación nacional uniformada; el otro pretendía resolver el problema financiero del Estado mediante la integración en el patrimonio de Hacienda de los bienes de la Corona y de las instituciones eclesiásticas, integración que no suponía necesariamente una modificación tan profunda de la estructura de la propiedad» ${ }^{32}$, línea que vencerá finalmente, dando lugar a una nueva aristocracia, mientras que las otras reformas deberán esperar: «la enfiteusis sólo desaparecería durante la I República y los foros antiguos no lo harán

${ }^{*}$ Es ésta una época que desconozco aún más que las otras en la historiografía portuguesa. M. H. Pereira me señala, entre los principales estudios sobre el liberalismo, los de Silva Días y el grupo de Coimbra, Sacuntala de Miranda sobre el septembrismo, o José Augusto Franco, Afonso de Barros, etc.

${ }^{31}$ En su II Seminario sobre «História Económica de Portugal no século xIX» intervinieron los profesores Alegría, Reis, Ramos, J. A. Nunes, H. A. Fonseca y M. H. Pereira.

${ }^{12}$ M. H. Pereira (1984), pp. 36-37. 
hasta 1976, casi siglo y medio después de la publicación de la ley por Mouzinhom.

Lo mismo ocurre con la política comercial exterior: revocado el duro tratado de 1810 con Inglaterra, Mouzinho promulga nuevos aranceles proteccionistas en 1837, pero en 1842 Costa Cabral favorece un nuevo tratado librecambista y desigual. $\mathrm{Y}$ concluye: «En un período decisivo de paso del capitalismo mercantil al capitalismo industrial, Portugal se había encontrado bruscamente desprovisto de un aparato de Estado nacional capaz de procurar soluciones que lo protegieran de la nueva competencia... La forma de inserción del capitalismo portugués en el sistema capitalista europeo durante el segundo cuarto del siglo XIX, determinaría, pues, que a la sociedad del Antiguo Régimen sucediera una sociedad capitalista dependiente» ${ }^{33}$.

En cuanto a la política industrial, señala la misma profesora en otro trabajo (1982) cómo la ruptura se produce también en 1834, con la supresión de la estructura jurídico-corporativa y la discusión sobre el nacionalismo o liberalismo económico: «Entre tanto, el desentendimiento entre la burguesía artesanal y la burguesía fabril, iba diseñando fracturas en el septembrismo, lanzando las simientes de movimientos cooperativos y mutualistas, y delineando los primeros pasos de una corriente republicana y socialista” ${ }^{34}$.

\section{IV.2. Comienzos del siglo $X X$}

El trabajo de A. Castro (1979), el de M. V. Cabral (1979), la útil guía de la I República de A. H. de Oliveira Marqués (1981), el estudio sobre su economía por J. M. Ferraz (1974) y el trabajo de A. J. Telo sobre su caída (1984), aportan abundantes y cuidadas informaciones económicas.

Manuel Villaverde Cabral, en su muy celebrado libro (1979) sobre los años del cambio de siglo, afirma el relanzamiento del crecimiento de las fuerzas productivas tras la crisis de 1890 , bajo la doble protección de la tarifa arancelaria y de la depreciación de la moneda y la orientación hacia la sustitución de importaciones. Se afirmará, así, de manera irreversible, «la dominación del modo de producción capitalista, y al mismo tiempo que daba origen a una constelación de contradicciones y conflictos que no cesarán de profundizar en las décadas siguientes. Las condiciones de vida se agravan bajo el proteccionismo, tanto para los trabajadores industriales cuanto para el campesinado, que emigra masivamentew.

${ }^{3}$ M. H. Pereira (1984), pp. 50-51.

4. H. Pereire (1982), p. 60. 
Sobre la agricultura en el primer cuarto del siglo -apunta Armando Castro $\left(1979,3 .^{a}\right.$ ed.) al crecimiento de la producción entre 1901-1903 y 1923-25 - se destacan: el trigo (13,4 por 100), el vino (13,3 por 100), aceite $(35,5$ por 100$)$ y corcho $(29,9$ por 100$)$, si bien descienden los demás cereales, a la vez que se atisban algunos cambios en la explotación por cuenta propia; de 230.000 has. así cultivadas en 1890 , se pasa a 351.000 en 1929; a su vez, los arrendamientos pasan de 210.000 a 280.000 en esos años, pero las aparcerías descienden de 110.000 a 68.000 en el mismo tiempo.

\section{IV.3. La I República}

En esta época tiene lugar - según A. Castro- «una nueva tentativa en el sentido de modernizar el sistema político mediante las transformaciones estructurales de la sociedad». Pero — concluye- «dado el carácter limitado del crecimiento de las fuerzas productivas nacionales, destacadamente las industriales, mantenidas en jaque tanto por la competencia internacional como por el enriquecimiento de las actividades mercantiles y especulativas, o por el atrincheramiento de los intereses de los grandes propietarios agrícolas, la exasperación de las luchas sociales y la radicalización del movimiento obrero harán aún más precaria, más problemática, una reforma del sistema político capaz de sobrepasar, dentro del cuadro liberal, los conflictos que obraban en el cuerpo de la sociedad"s.

Víctor de Sá ha estudiado los proyectos de reforma agraria (1983). También A. J. Telo (1984) estudia la I República y destaca el período de prosperidad 1915-25 para casi todos los sectores de la economía portuguesa; así lo muestra el número de nuevas sociedades ( 2.773 en 1920-29) y, sobre todo, el proceso de concentración empresarial, de modo que en 1926 «unas decenas de familias controlan una parte significativa de la economía portuguesa, muchas de ellas con intereses diversificados y recientes».

Sobre la década anterior a la dictadura (desde la entrada de Portugal en la Primera Guerra Mundial, y posguerrá) trata la tesis doctoral de Fernando Medeiros (dirigida en París por Pierre Vilar, defendida en 1976, editada en Lisboa dos años más tarde), en cierto modo continuando la ya citada de M. V. Cabral. Plantea Medeiros la estructura de la propiedad rural, y su distribución por zonas, entre el sur latifundista y el norte fragmentado aún más a partir de la abolición de los mayorazgos y la ley de sucesiones (1867). Describe el desarrollo del capitalismo agrario en torno al viñedo; la crisis agropecuaria de los años 80; el papel del millón de emigrados entre 1900 1926 en la articulación de los modos de producción; la lenta aparición de industrias modernas en los sectores textil, conservero, de abonos y moli- 
nería, alimenticias, corcho, etc., caracterizándose, por ejemplo, en la metalurgia, por sus reducidas dimensiones; o las grandes concentraciones empresariales y sus vinculaciones financieras.

\section{IV.4. «O Estado Novo»}

La época de la larga dictadura ha tenido un tratamiento reciente. Los primeros intentos de estudio global de la economía del salazarismo (aparte los aparecidos en plena época, como los de X. Pintado, 1964) son los de J. Mayer (1979) y Alfredo Marqués (tesis en Francia, 1980). Hay que mencionar, sectorialmente, los trabajos de Fernando Medeiros sobre los orígenes (1976, 1978), los de Nuno Valerio (1982, 1985) y F. Silveira (1982) sobre la economía entre guerras, el de Fernando Rosas sobre la primera etapa, 1926-38 (1986), el interesante encuentro sobre esa época, celebrado recientemente ( $1987 a$, tomo I) y los estudios de L. S. Matos (1973), M. B. Martíns (1976 a, b), R. R. Amaro (1982), A. Castro 1982), Nunes y Valerio (1983), J. Brandão de Brito $(1985)^{35}$, etc.

Durante mucho tiempo fue muy discutida la relativa fortuna de la dictadura en el terreno económico. R. R. Amaro (1982) combate la idea generalizada del marasmo económico en los primeros tiempos del salazarismo (hasta el final de la II Guerra Mundial), destacando, por el contrario, «la eficacia del régimen en cuanto a las posibilidades abiertas a la acumulación de capital», demostrable en un crecimiento medio anual del producto industrial de 4,8 por 100 entre 1933 y 1940; un crecimiento medio anual de la inversión industrial del 6,4 por 100 entre 1933 y 1938 (contra un 0,3 por 100 entre 1927 y 1933 , y un descenso del 12,1 por 100 anual entre 1938 y 1944). Claro que ese progreso del capitalismo llevó a «un agravamiento de la explotación de la fuerza de trabajo, gracias no a un aumento de la productividad, sino a una desvalorización de la fuerza de trabajo».

J. F. da Silveira (1982) coincide en los planteamientos de Amaro, destacando cómo *emergiendo de la crisis estructural que en los años veinte marcó profundamente la formación social portuguesa, el fascismo, al anteceder en algunos años al punto más depresivo de la crisis económica strictu sensu, pudo disponer, todavía, de un no despreciable margen de maniobra... En un primer momento el equilibrio presupuestario - llave maestra de la reorganización estatal - constituyó lógicamente el objetivo supremo de Salazar. La posterior agudización de la crisis con drásticas repercusiones sobre la crisis in-

35 Brandão de Brito es autor de una importante tesis, aún inédita, sobre la política económica entre 1939 y 1970. 
terna (supresión de las vitales remesas de los emigrantes, por ejemplo) determinará la necesidad de recurrir a un creciente intervencionismo estatal en el doble sentido de centralizar la vida económica y disciplinar las fuerzas productivas. Desde entonces, el Estado asume directamente la dirección del proceso de reconversión del capitalismo portugués» ${ }^{36}$.

Sobre la primera etapa de Salazar, el libro de Fernando Rosas (1986), del que apenas podemos resumir las conclusiones, plantea numerosas cuestiones teóricas de gran interés. El Estado Novo «se pretendía dotado de fuerza suficiente para desarticular las organizaciones obreras, arbitrar en las discordias políticas y económicas en el seno de los grupos dominantes y entre ellos y sus capas intermedias, y para adoptar las soluciones económicas y financieras de emergencia, intentando acudir a los sectores en crisis, reponer las tasas de lucro y garantizar la amenazada estabilidad general del sisteman. Pero el Estado Novo reposa sobre una realidad inestable; de ahí su doble política, de consenso entre los grupos dominantes (programa de estabilización financiera, por ejemplo), y de creciente intervención arbitral del Estado para concertar estrategias opuestas. Ello limitará las posibilidades de desarrollo del capitalismo y hará navegar entre contradicciones y equilibrios. «Políticas de protección y fomento industrial procurando no afectar los intereses agrarios; medidas de maximización de la producción y de los lucros de la gran agricuitura tradicional, sin tocar la estructura de la propiedad; políticas de fomento colonial, pero sin excesiva subordinación a una estrategia metropolitana de desarrollo integrado; esfuerzos - no siempre consecuentes o continuados - para hurtar los pequeños intereses de la producción artesanal al libre funcionamiento de las leyes de la concurrencia; tentativa permanente de compensar, generalmente de forma antieconómica, esto es, contraria a la lógica del desarrollo capitalista, cada sector perjudicado por las medidas adoptadas, para no ahondar situaciones de desequilibrio.»

Tampoco Rosas acepta ya seguir hablando, pura y simplemente, de estancamiento ruralisto en los años 30 , ignorando el indiscutible proceso de desarrollo y modernización de los sectores de base de la industria y de otros tecnológicamente más avanzados. Por ello prefiere hablar incluso de un «modelo de desarrollo» del Estado Novo, basado en la «estabilidad monetaria obtenida por el equilibrio presupuestario; en la protección de los mercados interno y colonial para la producción nacional, tendencialmente sustitutiva de las importaciones; en el apoyo a las exportaciones tradicionales; en el estímulo a las actividades productivas (por la baja de la tasa de interés, el abaratamiento del crédito, la tentativa de contener el desempleo y la política de desarrollo de las infraestructuras) y en la reanimación de la explotación

* J. F. da Silveira (1982), pp. 384-385. 
colonial» ${ }^{37}$. En cuanto a los estudios sobre el sector agrario destacan los de J. M. Pais (1976 y 1978) sobre la célebre «Campanha do Trigo" y de E. C. (1978) sobre la última etapa del salazarismo.

Un análisis de los proyectos y realizaciones de la política económica del Estado Novo ha sido hecho por A. B. Nunes y N. Valerio (1983) en torno a la ley de reconstitución económica, de 1935, en cuyo período de ejecución tiene lugar un innegable crecimiento del PIB, a una tasa media anual de 2,8 por 100 entre 1938 y 1950 , destacando el sector energético (6,4 por 100 anual). Una definición contundente sobre el régimen de la dictadura es la de Sacuntala de Miranda ${ }^{38}$ : «En la base de la política económica del Estado Novo, en los años 30 , existía un proyecto de autarquía, en gran medida semejante a los concebidos por otros fascismos europeos y más utópico quizá que éstos, si tenemos en cuenta que, además de basarse en la creencia de la perennidad del imperio colonial, minimizaba la importancia de los obstáculos representados por el flaco desarrollo de las fuerzas productivas nacionales, por la carencia de fuentes de energía autónomas y por la debilidad de los mercados metropolitanos y coloniales, entre otros.»

En cuanto a obras de sintesis, por razones obvias nos interesa especialmente la del norteamericano Eric M. Baklanoff (1980), que compara las economías de Portugal y España bajo los regímenes coetáneos y semejantes de Salazar y Franco. Destaca este autor el bajo nivel de paro contabilizado en plena Gran Depresión, en 1933: apenas el 1 por 100, y cómo el régimen corporativo supone la consagración de la propiedad privada, a la vez que una extensa actividad estatal. En efecto, «el Estado ejercía un amplio poder de hecho en relación con las decisiones de inversión privada y con el nivel de los tipos salariales. Un sistema de autorización industrial (el condicionamento industrial $)^{35}$, introducido mediante ley en 1931, hacía necesaria una autorización previa por parte del Estado para construir o para reubicar una factoría industrial, o para reabrirla». Por otra parte, recuerda algo bien conocido, que unas 40 grandes familias dominaban el sector privado, favorecidas por un sistema fiscal de bajos tipos impositivos sobre la riqueza y la herencia. Dentro de esa élite, diez familias controlaban los bancos comerciales más importantes y, desde allí, una gran parte de la economía nacional. Son los Champalimaud, los Espírito Santo, los Quina de Brito, los Pinto Basto y, sobre todo, los Melo, que a través de la CUF (Companhia União Fabril)

${ }^{37}$ F. Rosas (1986), pp. 278-283.

34 S. DE MIRANDA, «Crise económica, industrializaçäo e autarcia na década de 30\%, en la obra colectiva $O$ Estado Novo. Das origens ao fim da autarcia, 1926-1959, Viseu, 1987, tomo I, pp. 249-257. Este primer tomo de Actas del importante coloquio celebrado los días 4 a 6 de noviembre de 1986, en la Fundación Gulbenkian, contiene varios artículos mencionados en otro lugar o cuyo contenido se engloba en obras ya citadas.

* Véase J. M. Brandão de Brito (1985). 
controlaban el 20 por 100 de la producción industrial y, a través de sus 186 subsidiarias, generaban el 10 por 100 de la producción nacional.

Continuaba aún un sistema de propiedad agraria latifundista (o excesivamente dividida en el norte), de modo que un 1 por 100 de los propietarios, con fincas mayores a 50 has., poseía el 51 por 100 de las tierras de cultivo. Mientras, la industria seguía concentrada en torno a Lisboa-Setúbal (un 50 por 100 del total) y Oporto-Aveiro-Braga (un 30 por 100).

Ese modelo va a ir desmoronándose en los años 60 , ya que el sistema corporativo carecía de flexibilidad para adaptarse a nuevas empresas más complejas y dinámicas. Además, el comienzo de las guerras independentistas en Angola, Guinea y Mozambique (1961-64), obliga a Salazar a abrir la economía portuguesa al exterior, renovando su equipo de colaboradores económicos y emprendiendo importantes obras con ayuda exterior, tales como el complejo hidroeléctrico del Duero o el puente sobre el Tajo en Lisboa. En cuanto a las colonias, se intenta cambiar ese status y convertirlas en tierra portuguesa, favoreciendo las inversiones extranjeras, y desarrollando especialmente Angola, con sus importantes yacimientos de hierro, petróleo, diamantes, etc., de modo que poco antes de su independencia, en 1974, alcanzaba un PNB de cerca de 3.000 millones de dólares y una renta per capita de 500 dólares.

La etapa de 1960-1973 se caracteriza por importantes cambios, detectables. por ejemplo, en la reducción de la población activa agraria, del 44 al 28 por 100 , mientras la industrial pasa del 29 al 36 por 100. La participación en el PIB varía también del 26 al 13 por 100 en la agricultura y del 37 al 51 en la industria (especialmente la manufacturera, que triplica su valor añadido, siendo los sectores más dinámicos los metales básicos), así como la construcción. Una importante disminución de la población (un 0,6 por 100 anual), debido a la fuerte emigración ( 74 por 100 de la cual hacia la Europa industrializada; en 1970 emigran 180.000 portugueses) se traduce, lógicamente, en un mayor reparto de la renta per capita, a la vez que las remesas de los emigrantes llegan a alcanzar en 1972-73 1.100 millones de dólares, más de la mitad de las exportaciones portuguesas, un 30 por 100 de las divisas extranjeras, y alrededor del 10 por 100 de la renta nacional. Esas cuentas invisibles, junto a las del turismo (que pasa de 353.000 turistas en 1960 a más de 4.000 .000 en 1972, ya entonces más de la mitad españoles ${ }^{40}$ ),

${ }^{4}$ En cuanto a las relaciones con España o los escasos estudios comparativos entre los regímenes de Salazar y Franco, siempre limitándonos a la Historia Económica, apenas mencionaremos el viejo libro de J. M. Ruiz Morales (1946), un número de Información Comercial Española (1972), el libro ya citado de Eric M. Baklanoff (1980) o artículos como los también citados de Magda Pinheiro sobre ferrocarriles, el de A. N. da Silva (1982) en torno a la futura adhesión de ambos países al Mercado Común o las informaciones puntuales del Banco Exterior de España (1986). En ICE (1972) se repetía la queja 
habian hecho que el creciente déficit de la balanza comercial se convirtiera desde 1965 en superávit. Añadamos a ello que a partir de 1959 Portugal se convierte en miembro de la EFTA (tras cuya disolución, a partir de 1972, comienza las gestiones para el ingreso en el Mercado Común) y varios organismos internacionales como el FMI, el Banco Mundial y el GATT.

En la época de Marcelo Caetano, que sucede a Salazar manteniendo el esquema dictatorial (1968-1974), se insiste en ciertos rasgos liberalizadores de proteccionismos y monopolios anacrónicos, disminuyendo los controles sobre precios y las barreras comerciales, etc. Así, «durante los primeros años 70 , el contenido de la exportación portuguesa reflejaba una diversificación significativa entre los productos, incluyendo tanto bienes de consumo como de capital» y destacando como más dinámicas la metalurgia y maquinaria, material de transporte, pulpa y papel, ropa y calzado, y productos químicos, con un valor total del 43 por 100 de las exportaciones en 1972.

En esa época el PNB real creció a una tasa del 7 por 100 y la producción industrial en torno al 9 por 100 , y al comenzar la revolución de 1974 existían grandes planes industrializadores, destacando la envergadura del de la Península de Sines (un puerto industrial y una industria pesada, con una inversión de 1.200 millones de dólares). Por otra parte, la inversión exterior directa, apenas un 1 por 100 en 1959, había pasado al 27 por 100 de la formación bruta de capital, destacando Gran Bretaña, Alemania Federal y los Estados Unidos. Sobre las multinacionales publicó un breve trabajo M.. Belmira Martíns (1976 b), destacando la presencia de la gran mayoría de las grandes empresas mundiales: la ITT, la Ford, General Motors, Exxo, General Electric, Dow Chemical, Firestone, Westinghouse, etc., norteamericanas; las alemanas Hoechst, Siemens, Bayer, Basf, Grundig, AEG-Telefunken, Volkswagen; las inglesas ICI, BLMC, BP; las francesas Saint-Gobain, CGEThompson, Pechiney, Citroën; las holandesas Royal Dutch-Shell, Unilever, Philips, etc.; los grandes grupos farmacéuticos suizos, los suecos, japoneses, etc., para concluir que "la implantación de las multinacionales no correspondió a significativas transferencias de capital y tecnología, ni proporcionó un aumento relevante de la capacidad de exportación. Por otro lado, tal implantación fue siempre hecha fuera de cualquier plan de desarrollo de

del desconocimiento y lejanía de ambos países, aunque en 1971 las exportaciones españolas alcanzaban ya la cifra - pequeña, sólo un 2,7 por 100 del total vendido al extranjero, pero tres veces mayor que las portuguesas a España- de 80 millones de dólares, y tres millones de turistas españoles. El amplio déficit portugués se saldaba por la cuenta española con las colonias de Africa. Según estos informes, en 1969 la población activa agraria era el 31,5 por 100 , la industrial el 35,5 por 100 y la de servicios el 33 por 100 (cifras muy semejantes a las españolas: $30,7,37,1$ y 32,2 , respectivamente), y el PIB correspoñdiente era de 17,43 y 40 por 100 (mientras que el español: 15,35 y 50 , notablemente distinto). Una sintesis de gran interés: H. de la Torre Gómez (1988). 
nuestro país, sino más bien integrada en el plan de desarrollo de la multinacional" " 1 ".

Sobre este mismo asunto, es un arsenal de datos el libro de Armando Castro sobre O Sistema Colonial Portugués em Africa (1980 a), destacando la importancia del capital financiero y la concentración y el enorme papel de los capitales extranjeros en las colonias africanas: la prospección petrolífera era desde 1958 un monopolio norteamericano a través de la Standard Oil Company y la Gulf Oil Company. La Banca Morgan controla a través de la Diamang (creada en 1917) el trabajo del diamante de Angola. Las principales compañías ferroviarias son también norteamericanas; Gran Bretaña controla cientos de compañías $y$, aunque en menor escala, la presencia de capital belga, francés, etc., es también importante.

La etapa post-salazarista, y, sobre todo, a partir de 1974, escapa por razones obvias a nuestro repaso histórico, que esperamos (a pesar de lo apretado y aun apresurado de su presentación) contribuya a dar a conocer fuera de sus fronteras el buen hacer historiográfico de los colegas portugueses, cuva benevolencia espero, en todo caso. Su mejor logro estaría en conseguir abrir, aquí y allí, un debate sobre este «estado de la cuestión», que como en toda bibliografía debe advertirse está cerrado con una fecha: 29 de abril de 1988 .

\footnotetext{
" M." Belmira Martíns (1976 b), p. 61.
} 


\section{BIBLIOGRAFIA DE HISTORIA ECONOMICA DE PORTUGAL (SIGLOS XIX-XX) *}

AA. VV. (1980): "O Século xIx em Portugal», AS, 61.62 (coord. de Jaime Reis, M. F. Mónica y M. Ll. dos Santos). (Hay ed. en libro: Presença, S. A.)

AA. VV. (1981): «O movimento operário em Portugal», AS, 67.69 (coord. de M. F. Mónica y $M$. de F. Patriarca).

AA. VV. (1982): O liberalismo na Peninsula Ibérica na primeira metade do século XIX (coord. de M. H. Pereira).

AA. VV. (1982-83): "A Formação de Portugal contemporaneo», AS, 72-74 y 77.79.

AA. VV. (1985): Les Campagnes Portugaises de 1870 a 1930: image et realité, Actes du colloque Aix-en-Provence, 2-4 diciembre, 1982, París.

AA. VV. (1987 a): O Estado Novo. Das Origens ao Fim da Autarcia, 1926-1959, vol. I, Viseu.

AA. VV. (1987 b): «Estudos de História Económica de Portugal do século xIX», AS, 97.

AA. VV. (1988): Contribuições para a História do Pensamento Económico em Portugal.

Academia Portuguesn da Historia (1959): Guide de Bibliographie Historique Portugaise.

Alegría, Maria Fernanda (1983): Artículos en el colectivo del Centro de Estudos Geogràficos-INIC, $O$ desenvolvimento da rede ferroviária portuguesa $e$ as relaģoes com Espanba no século XIX.

- (1985): «A organização portuária portuguesa e a sua evolução de 1840 a 1910m, RHES, 15 , pp. 1.29 .

- (1987): A Organização dos Transportes em Portugal (1850-1910). As Vias e o Trátego.

Alexandre, Valentim (1979): Origens do Colonialismo Português moderno.

- (1986): «Um Momento Crucial do Subdesenvolvimento Português: Efeitos Económicos da Perda do Império Brasileiro», $L H, 7$, pp. 3-45.

Amaral, I., y Daveau, S. (1982): Bibliografía geográfica de Portugal, II.

Amaro, Rogério Roque (1982): «O Salazarismo na lógica do capitalismo em Portugal», $A S, 72.73-74$, pp. 995-1011.

Arroteia, Jorge Carvalho (1983): A emigração Portuguesa: Suas origens e Distribução.

- (1984): A evolução demografica Portuguesa: Reflexions e Perspectivas.

- (1985): Atlas da emigração Portuguesa, Sec. Est. Emigr. e das Com. Port. Lisboa.

Arruda, José Jobson de Andrade (1986): «O Brasil e a Crise Económica de Portugal na primeira década do século xIX», LH, 8, pp. 61-73.

Azevedo, J. Lucio de (1929): Epocas de Portugal Económico: Esboços de História.

Baklanoff, Eric M. (1980): La Transformación Económica de España y Portugal, Madrid.

BAPTISTA, F. Oliveira (1985): «Estruturas da produção agrícola: panorama do meio séculox, Pensamiento Iberoamericano, 8, pp. 331-365.

Barata, O. Soares (1985): «Demografia e evolução social em Portugal», AS, 87-88-89, pp. $981-993$.

Barros, A. do (1985): «O Latifundismo em Portugal», Pensamiento Iberoamericano, 8, pp. 391-402.

Bastín, Carlos (1984): *A Revista de Economía e a introdução do Keynesianismo em Portugal», Estudos de Economía, IV-2, pp. 163-184.

Bebiano, J. Bacelar (1960): O Porto de Lisboa (Estudo de História Económica).

Betrencourt, J. de Sousa (1961): O Fenómeno da Emigraçāo Portuguesa (1900-1957), Luanda.

* Sólo se indica el lugar de edición si no es Lisboa. Abreviaturas utilizadas en la cita de las principales revistas: $A S$, Análise Social; LH, Ler História; RHES, Revista de História Económica e Social. 
Bonifacio, M. Fátima (1980): Industrializaçāo oitocentista e concorrencia externa ( $A$ industria Chapeleira de 1814 a 1914) (extracto dactilogr.).

- (1984): «1834-42: A Inglaterra perante a evoluçāo política portuguesa (hipóteses para a revisão de versões correntes)», $A S, 83$, pp. 467-488.

- (1986): «A Associação Comercial do Porto no contexto político-económico nortenho e nacional (segundo cuartel do século xIX)», AS, 91, pp. 331-367.

- (1987): «Comércio Externo e Política Pautal na primeira metade do século XIX em Portugal», $L H, 10$, pp. $75-108$.

BoXER, C. R. (1981): O Império Colonial Português (1415-1825) (ed. inglesa: Londres, 1969).

Brito, J. M. Brandão de (1985): «Corporativismo e Industrialização: elementos para o estudo do condicionamento industrial", $L H, 6$, pp. 51-83.

Cabral, Manuel Villaverde (1974): Materiais para a História da Questão Agrária Em Portugal, Sec. XIX e XX, Porto.

- (1977): O Desenvolvimento do Capitalismo em Portugal no Sec. XIX.

- (1979): Portugal na alvorada do século 20: Forças Sociais, poder político e crescimento económico, $1890-1914$.

Capela, José.(1975): A Burguesia Mercantil do Porto e as Colonias (1834-1900), Porto.

- (1977): O imposto de palhota e a Introdução do modo de produção capitalista nas colónias, Porto.

Capela, José, y Papagno (1972): Colonialismo y feudalismo, Turín.

Carvalho, R. (1986): História do ensino em Portugal.

Castro, Armando (1974): A Dominaçāo inglesa em Portugal, Afrontamento (2." ed.), Porto.

- (1978 a): A Revolução industrial em Portugal no século XIX, Porto (es reedición de Introdução ao estudo da Economía Portuguesa, 1946).

- (1978 b): A Agricultura Portuguesa no Limiar da Reforma Agraria, Oeiras.

- (1979): A Economía Portuguesa do Século XX (1900-1925).

- (1980 a): O Sistema Colonial Português em Atrica (2." ed.).

- (1980 b): Estudos de História Sacio-Económica de Portugal, Porto.

- (1980 c): O pensamento económico no Portugal moderno.

- (1981): *As Finanças Públicas na Economía Portuguesa da Primeira metade do século XIXm, en O Liberalismo..., pp. 189-201.

- (1982): "A dinâmica económico-social portuguesa do pósguerra (1946-74), numa perspectiva teórico-crítica testemunhal», $A S, 72-74$, pp. 1013-1032.

- (1985): Historia económica de Portugal, 3 vols.

- (1987): Teoria do Sistema Feudal e Transição ao Capitalismo em Portugal.

Clarence-Smith, Gervase (1985): The third Portuguese empire, 1825-1975. A Study in economic imperialism, Manchester.

Costa, Ramiro da (1975): O desenvolvimento do capitalismo em Portugal.

- (1978-79): Elementos para a bistória do movimento operário, 2 vols.

Custodio, Jorge (1983): «Consideraçōes sobre Acúrsio das Neves, os Melhoramentos Económicos e a Industrialização Portuguesa», introducción a la reedición de J. Acúrsio Das Neves, Memória sobre os Meios de Melhorar a Indústria Portuguesa, pp. 7.72.

Cutilleiro, J. (1977): Ricos e Pobres no Alentejo (Uma Sociedad Rural Portuguesa).

Estevio, J. Antunes (1983): "A florestação dos baldíos», $A S, 77-78-79$, pp. 1157-1260.

EVANGELISTA, Joāo (1971): Um século de populaçāo portuguesa (1864-1960).

Extebank (1986): «Las relaciones económicas de España con Portugal», Boletín de Información Económica, 5, 4 pp., Madrid.

FeIJó, Rui (1984): Liberal Revolution, Social Change and Economic Development. The Region of Viana (Northwest Portugal), in the First Three Quarters of the Nineteenth Century (tesis doctoral inédita), Oxford.

Felo, Mariano (1948): Bibliografia Geográfica de Portugal, I (reedición en 1972).

- (1985): «Uma grande lavora de Serpa na segunda metade do século xIX», Finisterra, 40, pp. $207-266$.

Ferraz, José Manuel (1974): «O Desenvolvimento socioeconómico durante a primeira República (1910-1926)», AS, 42-43, pp. 454-471. 
Ferreira, A. Pinto, y Amorin, D. P. (1972): Preços de generos alimenticios comerciados nos mercados do Porto no sec. XIX (1844-1899), Porto.

Ferreira, Vítor Matias (1986): "Modos e Caminhos da Urbanização de Lisboa; a cidade e a aglomeraçāo de Lisboa, 1890-1940w, LH, 7, pp. 101-132.

Fisher, H. E. S. (1969): aAnglo-Portuguese Trade», en The Growth of English Overseas Trade in the $17 \mathrm{th}$ and $18 \mathrm{th}$ Centuries, Londres.

Fisher, H. E. (1984): De Methwen a Pombal. O comercio anglo-portugués de 1700 (ed. inglesa de 1971).

Fonseca, Carlos da (s.a.): Historia do movimento operário e das ideias socialistas em Portugal, 4 vols.

Fonseca, Helder Adegar (1983): «Senhorio, Rendeiros e Foreiros na Primeira metade do século xIX», LH, 2, pp. 15-39.

- (1984): Um empresário e uma empresa agrícola na 1." metade do século XIX. José Joaguim Teixeira e a Quinta do César no Carregado (Contributo para a história das empresas e empresários do século XIX português) (Memoria de licenciatura inédita), Evora.

- (1985): «Para uma tipologia de lavradores alentejanos. Os lavradores da comarca de Evora na primeira metade do século XIX», en Congreso sobre O Alentejo, vol. I: Semando novos rumos, Evora, pp. 205-213.

Franco, António de Sousa (1982): «Ensaio sobre as transformaçōes estruturais das finanças públicas portuguesas: $1900-80 », A S, 72,74$, pp. $1105-1140$.

Grrao, A. de Amorim (1945): «Origens e evoluçāo do urbanismo em Portugal», Revista do Centro de Estudos Demográficos, 1.

Godinho, V. Magalhāes (1955): Prix et monnaies au Portugal (1750-1850), París.

- (1970): Introdução a História económica.

- (1974): «L'émigration portugaise. Histoire d'une constante structurale», en Conjoncture économique, Structures sociales, París.

- (1978): «L'émigration portugaise ( $\mathrm{xv}^{*}-\mathrm{Xx}^{*}$ siècles). Une constante structurale et les réponses aux changements du mondew, RHES, 1, pp. 5-32.

- (1980): Estrutura da antiga sociedade Portuguesa.

Gomes, M. A.; BARros, H., y CAlDAS, E. (1944): "Traços principais de evolução da agricultura Portuguesa entre as duas guerras mundiaisw, Revista do Centro de Estudos Económicos, 1, pp. 20-203.

GUERREIRO, A. (1948): «A avalição do rendimento nacional português», Revista do Centro de Estudos Económicos, 7, pp. 123-150.

Guerreiro, A. D. (coord.) (1970): Bibliografía sobre a Economia Portuguesa.

Guimarnes, A. (1983): «A ideologia colonialista em Portugal no último quartel do século XIX», $L H, 1$, pp. $69-79$.

Hammond, R. J. (1966): Portugal and Africa, 1815-1910. A Study in uneconomic imperialism, Stanford.

Hanson, Carl A. (1981): Economy and Society in Baroque Portugal, 1778-1803, Londres.

Hespanhu, A. M. (1986): As vésperas do Leviathan. Instituiçōes e Poder Político. Portugal. Séc. XVII.

Informactón Comercial Española (1972): Páginas monográficas sobre Portugal, 461, pp. 41-76, Madrid.

Justino, David (1978): «Problemas de história dos preços: o sal e o milho no mercado de Aveiro (1862-1931)», RHES, 2, pp. 29-58.

- (1988): A formação do espacio económico nacional (Portugal, 1810-1913).

- (1987): *Acerca da evolução do PNB em Portugal (1850-1910)», AS, 97, pp. 451-461.

Kettenring, M. Ernest: $* A$ Bibliography of Theses and Disertations on Portugueses Topics. Completed in the United States and Canada 1861-1983*, en Portuguese studies international conference group on modern Portugal, núm. 4.

Laf́ns, Pedro (1985): O Sector exportador Portugués e a Economía Nacional (trabajo inédito), Sevilla (UIMP).

- (1986): «Exportaçōes Portuguesas, 1850-1913: A tese da Dependencia revisitada», AS, 91, pp. 381-419. 
Laf́ns, Pedro (1987 a): Indice da Produção agrícola em Portugal, 1845-1913 (inédito), I. C. S. Univ. de Lisboa.

- (1987 b): *Um caso mal sucedido de industrializaçāo "concorrencial" (Portugal: 18421913)», $A S, 97$, pp. 481-503.

- (1988): As condiçōes do progresso económico em Portugal (1850-1913): interpretação cuantitativa (en prensa, Banco de Portugal).

LEEDS, Anthony (1983): «Agricultura, política nacional, subdesenvolvimento e migração em tres regiöes de Portugal», $A S, 77-78-79$, pp. 1023-1043.

LEEDS, E. (1983): «Industrialização e emigração em Portugal: síntomas inevitáveis de uma doença estrutural $», A S, 77-78-79$, pp. 1045-1085.

Leire, J. Costa (1987): «Emigração portuguesa: a lei e os números (1855-1914)», $A S$, 97, pp. 463-480.

LimA, Marinus Pires de (1982): «Notas para uma história da organização racional do trabalho em Portugal: síntomas inevitáveis de uma doença estrutural», $A S, 72-74$, pp. 1299-1365.

Livi BACcI, M. (1971): A Century of Portuguese fertility, Princeton Univ. Press, Princeton. Macedo, Jorge Borges de (1951): A situação económica ao tempo de Pombal. Alguns aspectos, Porto.

- (1962): O bloqueio continental.

- (1982): Problemas de bistória da indústria Portuguesa no século XVIII (1." ed., 1963), Viseu.

MarquÉs, Alfredo (1980): La Politique Economique Portugaise dans la periode de la dictadure (1926-1974). Analyse des trois stratégies de l'etat (tesis doctoral), Univ. Grenoble II.

- (1981): Crescimento, desenvolvimento, exposição e critica dos conceitos, Coímbra.

Marqués, A. H. de Oliveira (1975): Antología da Historiografía Portuguesa, tomo II.

- (1977): História de Portugal, 2 vols. (4:" ed.).

- (1981): Guía da História da 1: República Portuguesa.

Martins, M." Belmira (1976 a): Sociedades e grupos em Portugal.

- (1976 b): As multinacionais em Portugal.

MatA, M:- Eugenia de Almeida (1984): A Unidade Monetária Portuguesa face d̀ Libra, 1891-1931 (documento de trabajo), Fac. de Economía, Univ. Nova.

- (1985): As finanças públicas Portuguesas da regeneragäo a primeira guerra mundial (tesis inédita), Univ. de Lisboa.

- (1986): «A Dívida Pública externa fundada de Portugal da Guerra Civil à Regeneração*, RHES, 18 , pp. 75-90.

- (1987): Cambios e politica cambial na economia Portuguesa, 1891-1931 (Cadernos de RHES, 1).

Matzus, M., y Mateus, A.: The Agrarian Revolution in 19th Century Portugal. Technological Cbange, Trade Regimes and the Response of Agriculture (documento de trabajo), Fac. de Economía, Univ. Nova.

Matos, A. C., y otros (1982): Senbores da terra: Diário de um agricultor alentejano (Prólogo de Jaime Reis).

Matos, Artur Teodoro (1980): Transportes e comunicaçōes em Portugal, Açores e Ma. deira (1750-1850), Ponta Delgada.

Matos, Luis Salgado (1973): Investimentos Estrangeiros em Portugal.

Mauro, Frederic (1970): Etudes économiques sur l'expansion portugaise, 1500-1900, París.

Mayer, J. (1979): Regional development in Portugal (1929-77). An Assessmen, Londres.

MEderRos, Fernando (1976): «Capitalismo e pre-capitalismo nos campos em Portugal no periodo entre as duas guerrasw, $A S, 46$, pp. 288-314.

- (1978): A Sociedade e a economía Portuguesas nas origens do Salazarismo.

Mendes, J. M. (1980): «Sobre as Relaçoes entre a indústria Portuguesa e a estrangeira no século xIX*, $A S, 61-62$, pp. 31-52.

Mendes, J. M. Amado (1984): A Area Económica de Coimbra. Estrutura e Desenvolvimento Industrial, 1867-1927, Colmbra. 
Mónica, M:' Filomena (1982 a): A formação da classe operária Portuguesa: Antología da imprensa operária (1850-1934).

- (1982 b): «Indústria e democracia: os operários metalúrgicos de Lisboa (1880-1934)», $A S, 72-73-74$, pp. $1231-1277$.

- (1985): O Movimento Socialista em Portugal (1875-1934).

- (1986): Artesãos e operários: Indústria, capitalismo e classe operária em Portugal (1870-1934).

Monteiro, Nuno (1985): «Lavradores de Forais. Revolução Liberal e regime senhorial na comarca de Alcobaça (1820-1824)», LH, 4, pp. 31-87.

Moral RuIz, Joaquín del (1979): «La independencia brasileña y su repercusión en el Portugal contemporáneo, 1810-1834m, en Gil Novales, A. (ed.): Homenaje a Noel Salomon, Barcelona, pp. 315-332.

- (1981): «La Hacienda Portuguesa en la crisis final del Antiguo Régimen, 1798-1833», en $O$ liberalismo na Peninsula Ibérica, pp. 175-187.

Morgado, N. A. (1979): «Portugal», en LEE, W. R. (ed.): European demographic and economic growth, Londres.

Morrow, D. W. (1973): «Phylloxera in Portugal», Agricultural History, 47.

Moura, F. P.; Pinto, L. M. P., y Nunes, A. (1954): «Estrutura da economía Portuguesan, Centro de Estudos Económicos, 14, pp. 7-219.

MüHLL, Urs von der (1982): «O mal portuguêst a dependência, causa do desenvolvimentow, $A S, 72-73-74$, pp. 1033-1036.

Nazareth, J. M. (1979): O Envelbecimento da populaçáo Portuguesa.

- (1985): «A demografia portuguesa do século xx: principais linhas de evolução e transformação», $A S, 87-88-89$, pp. 963-980.

Nazareth, J. M., y SousA, F. de (1983): A Demografía Portuguesa em finais do antigo regime (Cadernos de Rev. de História Económica e Social, 4).

Nogueira, César (1964-69): Notas para a bistória do socialismo em Portugal, 2 vols.

Nunes, A. J. Avelãs, y otros (1971): Sobre o Capitalismo Português, Coímbra.

Nunes, A. B., y VAlERIo, N. (1983): «A lei de reconstituição económica e a sua execução», Estudos de Economía, III-3, pp. 331-359.

O'NeIll, Brian Juan (1984): Propietários, lavradores e jornaleiras: Desigualdade social numa aldeia transmontana, 1870-1978.

Oliveira, Aurélio de (1987): «A História económica e social dos séculos Xvir-xvin na historiografía Portuguesa, 1974-1986», RHES, 20, pp. 113-131.

Oliverra, César de (1974): O Operariado e a república democrática (1910-1914).

Oliveira, Veiga de; Galhano, F., y Pereira, B. (1983 a): Alfaia agrícola portuguesa.

- $(1983 \mathrm{~b})$ : Sistemas de moagem.

- (1984): O linbo.

PAIS, José Machado, y otros (1976 y 1978): «O fascismo nos campos em Portugal: a Campanha do Trigo», $A S, 46$, pp. 400-474, y 54, pp. 321-389.

Pedreira, Jorge Miguel (1987): «Indústria e atraso económico em Portugal (1800-1825)», $A S, 97$, pp. 563-596.

Pereira, H. Caeiro (1985): Banco de Portugal: Do Passado ao Presente.

Pereira, Miriam Halpern (1969): «Demografía e desenvolvimento em Portugal na segunda metade do século xIX», $A S, 25-26$, pp. 85-117.

- (1974): Asimetria de crecimento e dependência exterior.

- (1975): «Niveaux de consommation et niveaux de vie au Portugal (1874-1922)», Annales, 2.3.

- (1978): «Decadência o subdesenvolvimento: uma reinterpretação das suas orígens no caso português», $A S, 53$, pp. 7-20.

- (1979 a): Politica e Economia. Portugal nos séculos XIX e XX. Comprende los trabajos citados anteriormente de 1974, 1975 y 1978 y los inéditos «Sobre la adecuación de los conceptos de Antiguo Régimen y Capitalismo al Portugal del Ochocientos» y «La I República: Proyectos y realizaciones».

- (1979 b): Revolução, finanças, dependéncia externa (de 1820 a convençäo de Gramido), Antologia. 
Pereira, Miriam Halpern (1981): A Politica Portuguesa de emigração (1850-1930). Estudio $y$ antologia.

- (1982): «O Estado vintista e os conflictos no meio industrial», en O liberalismo na Peninsula Ibérica na primeira metade do século XX, tomo II, pp. 33-63.

- (1983 a): Livre-Cambio e Desenvolvimento Económico. Portugal na segunda metade do século XIX (1." ed., 1971).

- $(1983 b)$ : «A crise do Estado de Antigo Regime: alguns problemas conceptuais e de cronologían, $L H, 2$, pp. 3-14.

- (1984): Politica y economia. Portugal en los siglos XIX y XX, Barcelona, Ariel (con. tiene los trabajos incluidos en la edición portuguesa de 1979 de Política e Economía..., más los de $1979 b$ y 1981).

- (1987): «Atitudes Políticas e Relações Económicas Internacionais na primeira metade do século XIX em Portugal», $L H, 10$, pp. 53-73.

- (1988): «Absolutismo reformista e nacionalismo: as negociaçōes para substituír o tratado de 1810 entre Portugal e a Inglaterra em 1824-1826m, en el libro colectivo Histoire de Portugal, Histoire Europèenne, Actas del Coloquio de París, $22-23$ mayo 1986, París, pp. 213-238.

Pereira, A. Ramos (1956): «O Mercado Monetário em Portugal no Periodo de 1931. 1955\%, Revista de Economía, IX, pp. 5-34.

Pery, G. (1979): «Estudos económicos. O Comercio externo de Portugal de 1800 a 1890 », RHES, 4, pp. 89-106.

Pimenta, Carlos (1983): «Salarios e Preços no século xIx em Portugal. Analise Económicaw, Boletim de CC. Económicas, XXVI, Coímbra.

PinHEIro, Magda de Avelar (1979): «Investimentos estrangeiros, política financeira e caminhos-de-ferro em Portugal na segunda metade do século XIX», AS, 58, pp. 265-286.

- (1983): «Reflexões sobre a história das finanças públicas Portuguesas no século XIX», LH, 1, pp. 47-67.

- (1987 a): Chemins de fer, Structure financière de l'Etat et Dèpendance exterieure au Portugal (1850-1890) (tesis doctoral inédita), París I-La Sorbona, 3 vols.

- $(1987 \mathrm{~b})$ : "Portugal e Espanha: Integração e ruptura. Os caminhos-de-ferro (18501890) $, L H, 11$, pp. 47-75.

Pintado, Xavier (1964): Structure and growth of the portuguese economy, EFTA, Ginebra.

RAfael, Francisco, y otros (1976): Portugal, capitalismo e o Estado Novo. Algumas contribuiçōes para o seu estudo, Porto.

Rato, M. H. Cunha (1983): «O colonialismo português, factor de subdesenvolvimento nacionalw, $A S, 77.78-79$, pp. $1121-1129$.

ReIs, Jaime: Portuguese industry, 1870-1913 (documento de trabajo), Fac. de CC. Eco. nómicas, Univ. Nova.

- (1980): "A "lei da fome": As origens do proteccionismo cerealifero (1889-1914)», en Agricultura litifundiaria na Península Ibérica, Oeiras, pp. 97-161.

- (1981): "Aspectos económicos de Viana do Castelo em 1840: um inquérito esquecido", Estudos Contemporâneos, 2-3, pp. 143-198.

- (1982): "Latifundio e progresso tecnico: a difusão da debulha mecanica no Alentejo, 1860-1930*, $A S, 71$, pp. $371-433$.

- (1984): "O Atraso económico Português em Perspectiva histórica (1860-1913)», AS, 80, I, pp. 7.28.

- (1985): A Produção industrial Portuguesa, 1870-1914. Primeira estimativa de um indice, Fac. de Economía, Univ. Nova.

- (1986): «L'Industrializacione di un paese che si eviluppa: il Portogallo del 1870 al 1913», Rivista di Storia Economica, Roma; trad. portuguesa: "A industrilalizaçāo num Pais de Desenvolvimento lento o tardío: Portugal, 1870-1913", AS, XXIII, 97 (1987), pp. 207-227.

- (1988): A evoluçäo do stock de Moeda Portuguesa, 1846-1914 (en prensa, Banco de Portugal).

RibeIro, Orlando (1963): Portugal, o Mediterrâneo e o Atlantico (2:" ed.).

Rosss, Fernando (1986): O Estado novo nos anos trinta. Elementos para o estudo da natureza económico-social do Salazarismo. 
Ruiz Morales, J. M. (1946): La economia del bloque bispano-portugués, Inst. de Estudios Políticos, Madrid.

SÁ, Víctor de (1981): Obras. Epoca Contemporánea, I, pp. 160-195.

- (1983): «Proyectos de reforma agrária na I República», $A S, 77-78-79$, pp. 591-610.

Santana, Francisco (1984): «Aspectos de inovação na Indústria Portuguesa durante a segunda metade do século xvill e o primeiro terço do século xIX», Anais Academia Portuguesa de História, vol. 29, II Serie.

Santos, F. Piteira: Geografía e Economía da Revolução de 1820 (3.2 ed.).

SERRAO, Joel (1959-62): Temas oitocentistas, 2 vols.

- (1973): Fontes de Demografia Portuguesa, 1800-1862.

- (1974): Emigração Portuguesa. Sondagem bistórica (2.* ed.).

- (comp.) (1977): Revolução Industrial e aceleraçāo da bistória.

- (1979): «Das Razōes históricas dos fracasos industriais Portugueses», Memorias de la $A C C C$, tomo XX, pp. 6-50.

- (dir.) (1985 a): Diccionário de História de Portugal, 6 vols., Porto.

- $(1985 b)$ : «Notas sobre a emigração e mudança social no Portugal contemporâneo», $A S$, 87-88-89, pp. 995-1004.

Serrao, J., y Martíns, G. (eds.) (1978): Da Indristria Portuguesa do Antigo Regime ao Capitalismo, Antología.

Serrao, J.; Leal, M. J. da Silva, y Pereira, M. H. (1983-85): Roteiro de Fontes da História Portuguesa Contemporánea, 3 vols.

Serrao, Joaquín Verissimo (1972): A Historiografía Portuguesa, 3 vols.

Shillington, V. M., y Chapman, A. B. (1907): The Commercial relations of England and Portugal, Londres.

SIDERI, Sandro (1961): Secular trends in the terms of trade between Portugal and the United Kingdom, 1854-1957, La Haya.

- (1978): Comercio e poder: Colonialismo informal nas relações Anglo-Portuguesas (ed. inglesa: Rotterdam, 1970).

SILBERT, Albert (1953): «Contribuição para o estudo do movimento dos preços dos cereais em Lisboam, Revista de Economia, VI-II, pp. 65-80.

- (1968): Le problème agraire portugais au temps des premieres Cortes liberales (1821. 1823), París.

- (1970): Do Portugal do antigo regime ao Portugal oitocentista (3." ed., 1981).

- (1978): Le Portugal mediterranéen a la fin de l'Ancien Regime: $18^{\circ}$-debut du $19^{c}$ siècle.

Silbert, Albert, y CASTRO, A. (1979): «Comentario» y «Algunas críticas», Historia E Ideias, 3.4 , pp. 5.11 y $11-18$, respectivamente, Porto.

Srlva, Antonio Neto da (1982): «Desequilibrios regionais e integração económica: Portugal, Grecia, Espanha e a adesão as comunidades europeias», Economia, VI-2, mayo, pp. 251-293.

Silva, Carlos da (1979): aAcerca da genese das relações de produçāo características do latifundio em Portugalo, en Agricultura latifundiaria na Peninsula Ibérica, Oeiras, pp. 47.96.

Silva, F. Marqués da (1970): O Povoamento da Metrópole observado dos censos 18641960.

SilvA, José Gentil da (1979): «L'autre versión des voyages de découverte: les portugais en quête d'urbanisme», Histoire et Civilisations Iberiques, 30, pp. 115-126, París.

- (1982): «O "Problema monetário Português" na compreensão de Portugal contemporâneo: entre a penúria e a especulação», $A S, 72-74$, pp. 977-993.

Silva, Manuela (1982): «Crescimento económico e pobresa em Portugal (1950-74)», AS, 72-74, pp. 1077-1086.

Silva, M.“ Beatriz Nizza da (1986): O Império Luso-Brasileiro, 1750-1822.

SilveirA, Joel Frederico da (1982): «Alguns aspectos da política económica do fascismo, 1926-1933w, en O fascismo em Poriugal. Actas do Coloquio 1980. 
SilveirA, Luis Espinha da (1980): «A venda dos bens nacionais (1834-43): Uma primeira abordagem», $A S, 61-62$, pp. 87-110.

- (1986): «Para um índice da produtividade do trabalho agrícola em Portugal na segunda metade do século XIX», RHES, 17, pp. 55-70.

- (1987): «Aspectos da evoluçāo das finanças públicas portuguesas (1800-1827)», $A S$, 97, pp. 505.529.

Sousı, Fernando de (1979): A população Portuguesa nos inicios do século XX (tesis doctoral), Porto.

Telo, Antonio José (1984): Decadência e queda da I República Portuguesa, tomo 2.

Tengarrinha, José Manuel (1981): «As greves em Portugal: uma perspectiva histórica do século xviII a 1920 , $A S, 67.69$, pp. $573-602$.

Tortella, Gabriel (1985): La bistoria económica comparada de los países del sur de Europa: los casos de España, Italia y Portugal, Alcalá de Henares.

Tortella, G., y Prados, L. (1984): The pattern of economic modernization in southern Europe (documento de trabajo), en el Curso de la UIMP, Sevilla.

TORRE GOMEz, H. de la (1988): "Las relaciones hispano-portuguesas. Una aproximación histórica e historiográfica», Bulletin d'Histoire Contemporaine de l'Espagne, 7, pp. 4053, Pau.

Universidad Internacional Menéndez y Pelayo (1984): Problemas bistóricos del desarrollo y atraso económico en la Europa del Sur: Italia, España y Portugal entre las décadas de 1830 y 1930, Curso dirigido por G. Tortella y L. Prados. Además de la suya, ponencias sobre Portugal a cargo de J. Reis, N. Valerio, P. Laíns, D. Justino (inéditas en casi todos los casos, se citan en sus autores).

Valente, Vasco Pulido (1982): "Os conserveiros de Setúbal», AS, 67-68-69.

VAlERIo, Nuno (1982): As finanças públicas Portuguesas entre as duas guerras mundiais (tesis doctoral inédita), Univ. de Lisboa.

- (1983): „O Producto nacional de Portugal entre 1913 e 1947», RHES, 11, pp. 89-102.

- (1984 a): A Moeda em Portugal, $1913-1947$ (Cadernos de RHES, 3).

- (1984 b): «A Companhia Confiança Nacional (1844-46)», RHES, 13, pp. 67-92.

- (1985): "The Portuguese economy in the inter-war period», Estudos de Economia, V, 2, pp. 143-147.

- (1986 a): *The role of the government in Portuguese economic growth, 1851-1939», Estudos de Economia, VII, pp. 63-69.

- (1986 b): «Expectativas dos credores externos sobre a solvabilidade do Estado português, 1881-1910», RHES, 18, pp: 1-8.

- (1987): «Aspectos das finanças públicas portuguesas: 1913-1983», en AA. VV. (1987 a), tomo 1 , pp. $275-300$.

Valerio, Nuno, y Mata, M." Eugenia (1982): «O Banco de Portugal, unico banco emisor (18S1-1931)», RHES, 10, pp. $49-69$.

Vieira Antonio Lopes (1980): «Âlgumas questōes sobre os transportes públicos da cidade de Lisboa nos finais do século XIX», AS, 61-62, pp. 71-86.

- (1981): «Investimentos británicos nos transportes urbanos e suburbanos em Portugal na segunda metade do século xIx. Fracasso e sucesso. A Lisbon Stem Tramways Company e a Lisbon Electric Tramways Companyw, RHES, 7, pp. 81-92.

- (1982 a): Os transportes públicos de Lisboa entre 1830 e 1910

- (1982 b): «Os transportes rodoviarios em Portugal, 1900-1980w, RHES, 5, pp. 57-94.

- (1983): The role of Britain and France in the finance of the Portuguese railways, 1845-1890 (tesis doctoral), Leicester.

- (1984): «Os caminhos de ferro antes dos caminhos de ferro : especulação ferroviária em Portugal em 1845-46», RHES, 15, pp. 123-134.

VIolante, Luis, y MoraIs, Joao (1986): Cronologia dos factos económicos e sociais. Portugal, 1926-1985, Livros Horizonte.

Wilson, Ch., y PARKer, G. (1985): Una introducción a las Fuentes de la Historia Económica europea, 1500-1800, cap. «Portugal», pp. 75-93, Siglo XXI, Madrid. 